\title{
Incorporation of satellite-derived thin-ice data into a global OGCM simulation
}

\author{
Takahiro Toyoda ${ }^{1}$ (D) Katsushi Iwamoto ${ }^{2,3,4} \cdot$ L. Shogo Urakawa ${ }^{1} \cdot$ Hiroyuki Tsujino ${ }^{5} \cdot$ Hideyuki Nakano $^{1} \cdot$ \\ Kei Sakamoto ${ }^{1}$. Goro Yamanaka ${ }^{1}$. Yoshiki Komuro ${ }^{6}$. Shigeto Nishino ${ }^{6}$. Jinro Ukita ${ }^{3}$
}

Received: 13 May 2019 / Accepted: 6 September 2019 / Published online: 14 September 2019

(c) The Author(s) 2019

\begin{abstract}
The presence of thin sea ice is indicative of active freezing conditions in the polar ocean. We propose a simple yet effective method to incorporate information of thin-ice category into coupled ocean-sea-ice model simulations. In our approach, the thin-ice distribution restricts thick-ice extent and constrains atmosphere-ocean heat exchange through the sea ice. Our model simulation with the incorporation of satellite-derived thin-ice data for the Arctic Ocean showed much improved representation of sea-ice and upper-ocean fields, including sea-ice thickness in the Canadian Archipelago and the region north of Greenland, mixed-layer depth over the Central Arctic, and surface-layer salinity over the open ocean. Enhanced sea-ice production by the thin-ice data constraint increased the total sea-ice volume of the Arctic Ocean by $5 \times 10^{3}-10 \times 10^{3} \mathrm{~km}^{3}$. Subsequent sea-ice melting was also enhanced, leading to the greater amplitude of the seasonal cycle by approximately $2 \times 10^{3} \mathrm{~km}^{3}$ ( $15 \%$ of the baseline value from the experiment without the thin-ice data incorporation). Overall, our results demonstrate that the incorporation of satellite-derived information on thin sea ice has great potential for the improvement of coupled ocean-sea-ice simulations.
\end{abstract}

Keywords Sea ice $\cdot$ Arctic Ocean $\cdot$ Thin sea ice $\cdot$ Ocean reanalysis

\section{Introduction}

Electronic supplementary material The online version of this article (https://doi.org/10.1007/s00382-019-04979-8) contains supplementary material, which is available to authorized users.

Takahiro Toyoda

ttoyoda@mri-jma.go.jp

1 Department of Atmosphere, Ocean and Earth System Modeling Research, Meteorological Research Institute, Japan Meteorological Agency, 1-1 Nagamine, Tsukuba, Ibaraki 305-0052, Japan

2 Arctic Environment Research Center, National Institute of Polar Research, Tachikawa, Japan

3 Faculty of Science, Niigata University, Niigata, Japan

4 City of Mombetsu, Mombetsu, Japan

5 Department of Climate and Geochemistry Research, Meteorological Research Institute, Japan Meteorological Agency, Tsukuba, Japan

6 Institute of Arctic Climate and Environment Research, Japan Agency for Marine-Earth Science and Technology (JAMSTEC), Yokosuka/Yokohama, Japan
Sea ice plays a pivotal role in the climate system. It covers roughly $8 \%$ of the total area of the world's oceans and acts as an important mediator in exchanges between the atmosphere and the ocean (McPhee 2008). Sea-ice formation greatly affects the stability of the ocean through the rejection of brine (e.g., Mauritzen et al. 2013). Heat and water vapor are vigorously transported from the ocean surface to the atmosphere in areas of sea-ice formation such as leads and polynyas. Therefore, such areas are key to understanding both oceanic-water-mass distributions and atmospheric circulation at high latitudes.

In an open-water region under cold and turbulent conditions, dense concentrations of frazil ice can develop rapidly in the surface layer to become thin ice (e.g., nilas and pancake ice). The thin ice then grows thicker and becomes pack ice, which is largely attributed to dynamical processes (e.g., Haas 2010). Thus, the presence of thin ice on open water is an observable indication of sea-ice formation. Therefore, the knowledge of thin-ice distributions is essential for 
Fig. 1 Sea-ice thickness distribution in the sea-ice formation region. a Schematic of the models representing thick ice only (blue) and both thin and thick ice (red). b Example of the comparison between the CTL and THIN experiments (blue and red, respectively) for $0.02 \mathrm{~m}$ thickness bins along the Canadian coast $\left(165^{\circ}-125^{\circ} \mathrm{W}\right.$, $69^{\circ}-73^{\circ} \mathrm{N}$ ) on November 01 , 2002 (a) Thickness distribution

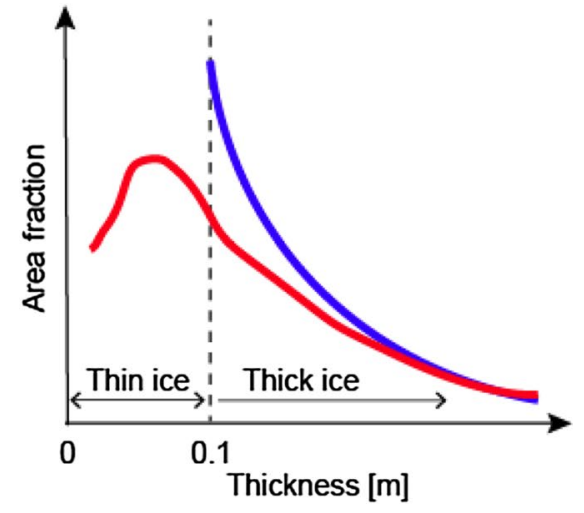

(b) Example from CTL and THIN

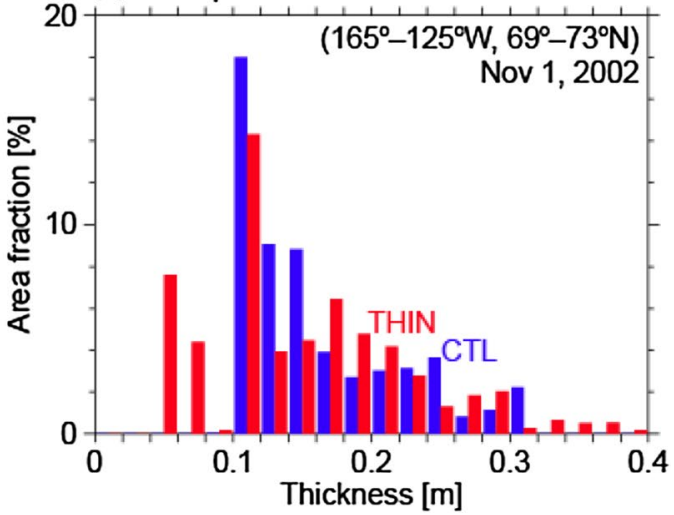

determining the effects of sea-ice formation processes on the ocean-sea-ice system.

Since the 1970s, passive microwave observations have provided information on the spatial coverage of sea ice (e.g., Cavalieri et al. 1999). Cavalieri (1994) and Martin et al. (1998) proposed that the thickness of thin sea ice could be estimated from passive microwave measurements because of their sensitivity to the salinity of the newly formed sea ice (Naoki et al. 2008). This approach has been used for thin-ice thickness retrieval up to $10-20 \mathrm{~cm}$ in several regions with the empirical retrieval algorithms different from study to study due to different sensors and regions used (see Makynen and Simila 2019). These estimates have been used to quantify sea-ice production in coastal polynyas (e.g., Tamura and Ohshima 2011). Recently, Iwamoto et al. (2014) estimated the thin-ice thickness distribution in the Arctic Ocean by using microwave data from the Advanced Microwave Scanning Radiometer on the Earth Observing System satellite (AMSR-E). The long-term daily thin-ice dataset covering the whole Arctic Ocean (Iwamoto et al. 2014) should be useful for examining the effects of sea-ice formation processes in an ocean-sea-ice simulation.

Ocean general-circulation models (OGCMs) have successfully been improved to describe the gross features of sea-ice variability (e.g., Proshutinsky et al. 2011), thereby enhancing our understanding of ocean-sea-ice processes in the polar regions (e.g., Holland et al. 2001). Observation information was incorporated into the ocean-sea-ice simulations through data-assimilation approaches (e.g., Meier et al. 2000; Lindsay and Zhang 2006). The intercomparison of the data-assimilation products (Chevallier et al. 2017; Uotila et al. 2019) indicated that robust reproduction of water-mass distributions, ocean stratification, and sea-ice thickness have not yet been achieved for either the Arctic or Southern (Antarctic) Ocean, which can be attributed to limited observations and inaccuracies in the model parameterizations and atmospheric forcing. In spite of the recognized importance of the sea-ice-formation processes in determining the heat and freshwater budgets in the ocean-sea-ice system as described above, the thin-ice category has not been directly represented in OGCMs, with or without data-assimilation. Under freezing conditions, relatively thick ice with a minimum thickness as defined in the models (e.g., $0.1 \mathrm{~m}$ as in this study) is formed in OGCM simulations, which can greatly alter the surface cooling from that expected for such conditions for both thin- and thick-category ice distributions (Fig. 1a), which can often be described by means of lognormal functions (e.g., Haas 2010; Rabenstein et al. 2010).

In this study, we aimed to incorporate thin-ice information (of 0-0.1 m thick) from satellite-derived data (Iwamoto et al. 2014) into an ocean-sea-ice simulation as a first attempt to apply these thin-ice data in a modeling study. One way to incorporate the data would be to add a new prognostic variable for thin ice to the model and then refine it through a data-assimilation approach. However, the adequate representation of thin ice (i.e., comparable to the observational data) as a prognostic variable, e.g. the calculation of the concentration of frazil ice (e.g., Matsumura and Ohshima 2015), would require complicated modeling. Construction of a model that would yield thin-ice evolution over time, thus making correction by data assimilation meaningful, was beyond the scope of this study. Therefore, instead of a data-assimilation approach in the strict sense, we devised a simple method to utilize the thin-ice data to set boundary conditions for the model (as fixed input parameters). We then investigated the impact of this constraint on the modeled ocean and sea-ice variables. Because the thin-ice data reflect the occurrence of sea-ice formation as described above, we expected the reproduction of both thick-sea-ice distribution and ocean-water properties to be improved.

The structure of this article is as follows. After a description of the data and model described in Sect. 2, we present a method for incorporating the thin-ice data into the model in Sect. 3. Then we present and discuss results in Sect. 4 and provide summarizing comments and our conclusions in Sect. 5. 


\section{Data, model, and experiments}

\subsection{Data}

We used daily time series of thin-ice thickness $(0-0.2 \mathrm{~m})$ in the Arctic Ocean derived from passive microwave observations made by AMSR-E during 2002-2011 (Iwamoto et al. 2014), provided by the National Institute of Polar Research, Japan. ${ }^{1}$ The resolution of the data is $6.25 \mathrm{~km}$ based on the 89-GHz channel, which well represents the subgrid-scale distribution for our model and hence is suitable for calculating the fractional coverages on the model grids as described below. Influences of water vapor and cloud liquid water were removed by using the $36-\mathrm{GHz}$ channel, whereas noise due to thick landfast ice was eliminated by using the verticalpolarization gradient ratio between the two channels. Iwamoto et al. (2014) reported that an overall uncertainty of the thin-ice thickness estimate was approximately $0.03 \mathrm{~m}$ $(0.06 \mathrm{~m})$ for the $0-0.1 \mathrm{~m}(0.1-0.2 \mathrm{~m})$ thickness range. The estimate has also been validated by using in situ data (Fukamachi et al. 2017).

We used atmospheric reanalysis (JRA-55) data ${ }^{2}$ (Kobayashi et al. 2015) and satellite-based sea-surface temperature data ${ }^{3}$ (MGDSST) (Kurihara et al. 2006) for preprocessing the thin-ice data, as described in Sect. 3.1. To calculate the surface-heat, freshwater, and momentum fluxes to drive the model, we used downward shortwave and longwave radiation, precipitation, 10-m air temperature, specific humidity, and 10-m wind fields from the 3-h JRA55-do dataset ${ }^{4}$ (Tsujino et al. 2018). The JRA55-do dataset, which is based on the JRA-55 atmospheric reanalysis, was constructed specifically to provide forcing data for driving ocean models and includes corrections for global heat and freshwater budget balances.

For comparison with our results on sea-ice fields, we used observational sea-ice thickness data (Yi and Zwally 2009) acquired by the Geoscience Laser Altimeter System (GLAS) on the Ice, Cloud, and Land Elevation Satellite (ICESat) and Special Sensor Microwave/Imager. Data for the GLAS campaign periods ${ }^{5}$ were provided by the National Snow and Ice Data Center.

We also used the Monthly Isopycnal/Mixed-Layer Ocean Climatology (MIMOC) dataset ${ }^{6}$ (Schmidtko et al. 2013)

\footnotetext{
${ }^{1}$ See https://ads.nipr.ac.jp/kiwa/Summary.action?selectFile=A2014 1120-001.

2 See http://jra.kishou.go.jp/JRA-55/index_en.html.

3 See http://ds.data.jma.go.jp/gmd/goos/data/rrtdb/jma-pro/mgd_sst_ glb_D.html.

${ }^{4}$ See https://climate.mri-jma.go.jp/ htsujino/jra55do.html.

5 See https://nsidc.org/data/NSIDC-0393.

${ }^{6}$ See https://www.pmel.noaa.gov/mimoc/.
}

provided by the National Oceanic and Atmospheric Administration, USA.

Temperature and salinity profiles based on conductivity-temperature-depth (CTD) measurements obtained on the R/V Mirai cruises (e.g., Nishino et al. 2013) were provided by the Japan Agency for Marine-Earth Science and Technology. ${ }^{7}$ These in situ salinity observations as well as the MIMOC mixed-layer depths (MLDs) were used for validation of our results in representing the oceanic field.

For data assimilation, in situ temperature and salinity data were obtained from the Ensemble 4 dataset $^{8}$ (Good et al. 2013), World Ocean Database $2013^{9}$ (Boyer et al. 2013), and Global Temperature-Salinity Profile Program database ${ }^{10}$ (Hamilton 1994). Satellite-based sea-surface height anomalies ${ }^{11}$ (CLS 2012), sea-surface temperatures (MGDSST), sea-surface salinities ${ }^{12}$ (NASA Aquarius project 2017), and sea-ice concentrations (MGDSST) were also assimilated. (However, when and where thin-ice exists, sea-ice concentration data was not assimilated locally; see Sect. 3.2.)

\subsection{Model}

The OGCM used in this study was the Meteorological Research Institute Community Ocean Model (MRI.COM) v.4 (Tsujino et al. 2017). The experiments were conducted within the GONDOLA_100 framework (Urakawa et al. 2017). The model domain covers the whole global ocean. South of $64^{\circ} \mathrm{N}$, the horizontal resolution is $1^{\circ}$ of longitude and $0.3^{\circ}-0.5^{\circ}$ of latitude (finer around the equator), and for north of $64^{\circ} \mathrm{N}$, we adopted a bipolar grid (Murray 1996) with polar singularities at $80^{\circ} \mathrm{E} 64^{\circ} \mathrm{N}$ and $100^{\circ} \mathrm{W} 64^{\circ} \mathrm{N}$ on land. We defined 60 vertical levels and a bottom boundary layer. The model is driven by surface-heat and freshwater fluxes and by surface stresses, which were calculated from the surface conditions according to the JRA55-do (Tsujino et al. 2018) and Large and Yeager's (2009) bulk formulas.

The sea-ice model embedded in the OGCM describes both the thermodynamics and dynamics of sea ice. The seaice thermodynamics part of the model, based on Mellor and Kantha (1989), considers the heat capacity of sea ice (onelayer ice and zero-layer snow). Other processes (categorization by thickness, ridging, rheology, and albedo parameterization) are based on the Los Alamos sea-ice model

\footnotetext{
${ }^{7}$ See http://www.godac.jamstec.go.jp/darwin/e.

${ }^{8}$ See https://www.metoffice.gov.uk/hadobs/en4/index.html.

9 See https://www.nodc.noaa.gov/OC5/WOD13/.

${ }^{10}$ See https://www.nodc.noaa.gov/GTSPP/.

${ }^{11}$ See https://www.aviso.altimetry.fr/en/data/products/sea-surfaceheight-products/global/sla-h.html.

12 See https://podaac.jpl.nasa.gov/dataset/AQUARIUS_L3_SSSRainFlagged_SMI_DAILY_V5.
} 
Table 1 Parameter settings in sea-ice model

\begin{tabular}{ll}
\hline Parameter & Value \\
\hline Scaling factor for ice pressure $P^{*}($ Hibler 1979) & $2.75 \times 10^{4} \mathrm{~N} \mathrm{~m}^{-2}$ \\
e-folding constant for ice pressure $C$ (Hibler and Walsh 1982) & 20 \\
Air-ice drag coefficient $C d_{a i}$ (Large and Yeager 2004) & $1.63 \times 10^{-3}$ \\
Cold ice albedo (near-infrared wavelength) & 0.36 \\
Cold ice albedo (visible wavelength) & 0.78 \\
Reduction rate of albedo for melting ice (both wavelengths) & $-0.075 /{ }^{\circ} \mathrm{C}$ \\
Cold snow albedo (near-infrared wavelength) & 0.70 \\
Cold snow albedo (visible wavelength) & 0.98 \\
Reduction rate of albedo for melting snow (near-infrared) & $-0.15 /{ }^{\circ} \mathrm{C}$ \\
Reduction rate of albedo for melting snow (visible) & $-0.10 /{ }^{\circ} \mathrm{C}$ \\
Thermal ice conductivity & $2.04 \mathrm{~J} \mathrm{~m}^{-1} \mathrm{~s}^{-1} \mathrm{~K}^{-1}$ \\
Thermal snow conductivity & $0.31 \mathrm{~J} \mathrm{~m}^{-1} \mathrm{~s}^{-1} \mathrm{~K}^{-1}$ \\
Salinity of thick sea ice & 4
\end{tabular}

(Community Ice Code, CICE, version 3.14; Hunke and Lipscomb 2006; see also Hunke and Lipscomb 2010). Five sea-ice thickness categories $\left(N_{c}=5\right)$ are allowed within a grid cell (Lipscomb 2001): 0-0.6 m, 0.6-1.4 m, 1.4-2.4 m, 2.4-3.6 m, and 3.6-30.0 m (hereafter, referred to as categories $1-5$, respectively). Note that the minimum thickness of the 1 st category was set to $0.1 \mathrm{~m}$.

Albedo values are defined for both sea ice and snow as $>700 \mathrm{~nm}$ for near-infrared and $<700 \mathrm{~nm}$ for visible wavelengths. We considered the surface melting effect (air temperature $>-1{ }^{\circ} \mathrm{C}$ ) for decreasing these albedos. The mean surface albedo, $\alpha_{I}$, is calculated from the area fractions of snow and bare ice for each category. When ice thickness $h$ is less than the reference thickness ( $h_{\text {ref }}$ set to $0.5 \mathrm{~m}$ ), the albedo of the ice is reduced as

$\alpha_{\text {thin }}=\alpha_{o}+\beta\left(\alpha_{I}-\alpha_{o}\right)$,

where $\alpha_{o}$ is the albedo of the ocean and $\beta=\arctan \left(a_{r} h\right) / \arctan \left(a_{r} h_{r e f}\right)$ with a constant $a_{r}=4.0$. Part of the absorbed shortwave radiation penetrates the ice as

$I(z)=I_{0} \exp \left(-\kappa_{i} z\right)$,

where $I(z)$ is the shortwave flux that reaches depth $z, I_{0}$ is the surface flux, and $\kappa_{i}$ is the bulk extinction coefficient (set to 1.4). Basic parameter values in the sea-ice model are shown in Table 1.

\subsection{Experiments}

We conducted a baseline experiment (hereafter referred to as $C T L$ ) for the period 1958-2017 after spin-up integration with a 3-dimensional variational data assimilation (Toyoda et al. 2015, 2016). In addition, we conducted an experiment incorporating thin-ice data for the period from July 2002 to September 2011 (hereafter referred to as THIN). For the THIN experiment, the initial conditions and settings (except for thin ice) were taken from the CTL experiment. The method to incorporate the thin-ice information is described in Sect. 3.2.

\section{Incorporation of thin-ice data}

\subsection{Preprocessing}

We applied preprocessing to the original thin-ice data (the unprocessed data retrieved by Iwamoto et al. (2014)) for use in the model mainly as follows. First, we calculated thin-ice mean thickness and area-fraction values on the model grids from the original data. Second, we removed noise, mainly thick ice that had been thinned by melting.

We utilized thin-ice data in the thickness range $0-0.1 \mathrm{~m}$ to constrain the model. Although the original dataset provides thicknesses in the range $0-0.2 \mathrm{~m}$, we chose the more-limited range in part because the uncertainty of the satellite-data retrievals increases rapidly with ice thickness (e.g., Iwamoto et al. 2013). The narrower thickness range (0-0.1 $\mathrm{m}$ thick of thin ice as defined in this study) also complemented the minimum thickness of the modeled (thick) sea ice of $0.1 \mathrm{~m}$ in the sea-ice module of our OGCM. In contrast to the thin ice, which corresponds to the ice represented by the data from Iwamoto et al. (2013), ice with a thickness greater than $0.1 \mathrm{~m}$ is represented as a prognostic variable in our model and is hereafter referred to as thick ice.

First, we estimated the thin-ice thickness and area fraction on the model grids from the original thickness information with a resolution of $6.25 \mathrm{~km}$. About 30-60 original data grids were included within each model grid for the Arctic Ocean. Taking into account the retrieval errors of the original data, the probability density function $p_{m}$ of thickness $h$ around the original data $h_{m}$ is defined as 
Fig. 2 Time series of the thinice area $(\mathbf{a}, \mathbf{b})$ and volume (c, d) in the Arctic Ocean (north of $65^{\circ} \mathrm{N}$ ) during the period July 01 , 2002, to September 30, 2011 $(\mathbf{a}, \mathbf{c})$ and mean annual cycles for this period $(\mathbf{b}, \mathbf{d})$. Blue lines indicate estimates from original thin-ice $(0-0.1 \mathrm{~m})$ data (Iwamoto et al. 2014) with an assumption of binary (full-grid/ zero) distribution of the thin-ice existence; red lines indicate the estimates after processing to remove noise
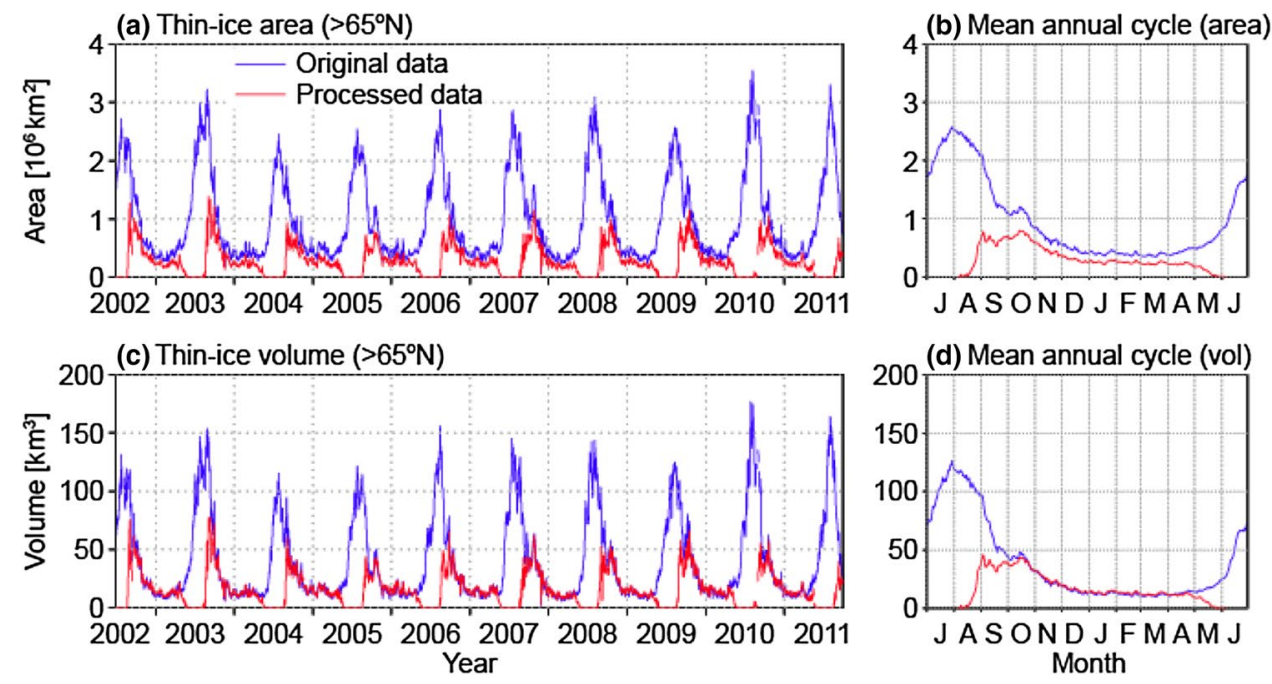

$p_{m}(h)=\frac{1}{\sqrt{2 \pi} \sigma_{h}} \exp \left(-\frac{\left(h_{m}-h\right)^{2}}{2 \sigma_{h}^{2}}\right)$

where $m$ is the data number and $\sigma_{h}$ is the retrieval error. For practical reasons, a Gaussian distribution was assumed, although in reality the error distribution would be asymmetric. Iwamoto et al. (2014) reported that the standard deviation of their retrievals from the reference data was about $0.03 \mathrm{~m}$ for the thickness range $0-0.1 \mathrm{~m}$ and also that the value differed among regions. For example, the standard deviation and bias for the Chukchi Sea were $0.039 \mathrm{~m}$ and $+0.008 \mathrm{~m}$, respectively, whereas both values were smaller in the Laptev Sea and northern Baffin Bay (Iwamoto et al. 2014). Hence, we assumed $\sigma_{h}$ to be $0.04 \mathrm{~m}$ $\left(\sim \sqrt{0.039^{2}+0.008^{2}} \mathrm{~m}\right)$ in this study.

We calculated the thin-ice area fraction $\left(a_{\text {thin }}\right)$ and mean thickness $\left(h_{\text {thin }}\right)$ on the model grids by using the original data located within the model-grid spacing $(m=1, \ldots, M)$. Since we assumed the probability density distributions around the data (3), we used all original data in the $0-0.2 \mathrm{~m}$ range to estimate these values (for thin ice of the thickness range $0-0.1 \mathrm{~m}$ ) as:

$a_{\text {thin }}=\frac{1}{M} \sum_{m=1}^{M} \int_{0 \mathrm{~m}}^{0.1 \mathrm{~m}} p_{m}(h) d h$,

$h_{\text {thin }}=\frac{1}{a_{\text {thin }}} \cdot \frac{1}{M} \sum_{m=1}^{M} \int_{0 \mathrm{~m}}^{0.1 \mathrm{~m}} h \cdot p_{m}(h) d h$.

Second, we excluded data considered erroneous, mainly due to the influence of melting ice. Although Iwamoto et al. (2014) and other previous studies focused on freezing ice, the dataset actually includes data from the melting season. For example, the total area and volume of thin ice in the Arctic Ocean (north of $65^{\circ} \mathrm{N}$ ) estimated from the original data increase greatly in summer (Fig. 2). Determination of whether detected thin ice is new ice or thick ice that has been thinned by melting is difficult with an algorithm like that was used for thin-ice thickness based on AMSR-E data, such as those by Tamura et al. (2007) and Tamura and Ohshima (2011), although their algorithms targeted new ice only.

We removed the influence of melting ice and noise probably due to cloud cover (e.g., Fig. S1) as much as possible by using data from two independent datasets, JRA-55 and MGDSST; we used the following conditions to determine whether the thin-ice data were affected by melting ( 1 and 2 ) or cloud cover (3 and 4):

1. Net surface-heat flux (JRA-55) is downward.

2. Surface air temperature (JRA-55) is greater than $-1{ }^{\circ} \mathrm{C}$.

3. Sea-surface temperature (MGDSST) exceeds $0{ }^{\circ} \mathrm{C}$ in the corresponding grid or on average over an area within $200 \mathrm{~km}$ of the grid.

4. No sea ice (MGDSST) exists within $200 \mathrm{~km}$ of the grid.

(Note that conditions 1 and 2 mostly overlapped, triggering error flags.)

Even after this processing, the thin-sea-ice area was overestimated for the Okhotsk Sea, compared with results reported by Nihashi et al. (2009), reflecting differences in the dominant ice types between the Arctic and subarctic regions as discussed by Iwamoto et al. (2013). Therefore, in our study, data from the Okhotsk Sea were removed.

Another issue was that original data were not available for some days (43 of the total of 3379 days). The area fraction and mean thickness data for these days were linearly interpolated from existing data. We also removed data for 
ice with mean thickness of less than $0.01 \mathrm{~m}$, resulting from the above preprocessing.

The total area and volume of thin ice in the Arctic Ocean thus were greatly reduced from the original data values (Fig. 2). In particular, we removed most of data from each year's melting season. Note that the filtering of the melting ice was adopted by using local conditions (e.g., surface air temperature) instead of selecting specific months (e.g., from October to April; Kaleschke et al. 2016), which allowed removal of the data with melting conditions even in such months (October-April) and maintenance of the data with freezing conditions even in the months that melting takes place in a basin scale (May-September). The thin-ice area increases from the end of August and becomes greater than $0.5 \times 10^{6} \mathrm{~km}^{2}$ in September and November, when the seaice cover continues to increase in the Arctic Ocean. The time evolution of the thin-ice volume is consistent with that of the thin-ice area. The total sea-ice area and volume (including both thin and thick ice) are considered to be about $5 \times 10^{6} \mathrm{~km}^{2}$ and $4000 \mathrm{~km}^{3}$, respectively, in summer and $11 \times 10^{6} \mathrm{~km}^{2}$ and $16,000 \mathrm{~km}^{3}$, respectively, in winter, not including the Canadian Archipelago (e.g., Laxon et al. 2013). These values are thus much larger than those of the thin-ice values.

\subsection{Incorporation into the model}

The thin-ice area fraction $\left(a_{t h i n}\right)$ and thin-ice thickness $\left(h_{\text {thin }}\right)$ were interpolated at each time step from the daily data and used to constrain the model as described below.

Zero-layer thermodynamics was assumed for the thin ice. Thus, heat fluxes at the top and bottom of thin ice were calculated under the assumption of thermal equilibrium. Latent- and sensible-heat fluxes and upward longwave radiation at the ice top were calculated by using the same bulk formulas as for thick ice (Large and Yeager 2009). Albedo values for the thin ice were calculated by Eq. (1) using $\beta=\arctan \left(a_{r} h_{\text {thin }}\right) / \arctan \left(a_{r} h_{\text {ref }}\right)$ to be about $0.34(0.18)$ for $h_{\text {thin }}$ equal to $0.1 \mathrm{~m}(0.05 \mathrm{~m})$; they are thus smaller than thick-ice-albedo values. Shortwave-radiation penetration was also determined in the same way as for thick ice, by Eq. (2). Because the shortwave-radiation flux is generally small in the freezing season, the offsetting effect of the shortwave insolation to increase total surface heat flux is relatively small. Overall, a greater freezing rate for ocean water is expected through thin ice than through thick ice (because thin ice has a smaller insulating effect). Snow on thin ice was not considered, and precipitation was assumed to fall into the ocean water.

Thin ice was assumed to cover the open ocean and restrict the extent of thick ice. Thus, we set the upper limit for the area fraction of the modeled thick sea ice to $1-a_{\text {thin }}$ instead of to the full-grid value of 1 set in the baseline experiment. When the sum of the thin- and thick-ice areas became greater than the full-grid spacing $\left(a_{\text {thick }}+a_{\text {thin }}>1\right.$, where $a_{\text {thick }}=\sum_{n=1}^{N_{c}} a_{n}$ is the area fraction of thick ice with the categorized values $a_{n}$, $n=1, \ldots, N_{c}$ ), the thick-ice area was reduced (with the thinice area fixed by the data) until the summed area was equal to the grid spacing. This reduction corresponds to ridging/rafting around polynyas in our coarse-resolution model. The resulting thick-ice area fraction in each category is

$a_{n}^{\text {new }}=a_{n}-\left(a_{\text {thick }}+a_{\text {thin }}-1\right) \times \frac{a_{n}}{a_{\text {thick }}}$,

where the new indicates the value after the reduction process. In changing the thick-ice area fraction, the thicknesses of thick ice and snow $\left(h_{n}\right.$ and $h_{\text {snow }}$, respectively) were modified while conserving their volumes:

$h_{n}^{\text {new }}=h_{n} \times \frac{a_{n}}{a_{n}^{\text {new }}}$,

$h_{\text {snow }}^{\text {new }}=h_{\text {snow }} \times \frac{a_{\text {thick }}}{a_{\text {thick }}^{\text {new }}}$.

Note that, in addition to the above influence of the thin ice, all the model dynamical/thermodynamical processes and the redistribution into the thickness categories were applied for the thick ice as in the CTL experiment.

Sea-ice pressure $P$ (Hibler 1979), which is used to determine the sea-ice velocity in the rheology parameterization, was modified by including the effect of the thin ice as follows:

$P=P^{*}\left(\sum_{n=1}^{N_{c}} a_{n} h_{n}+a_{\text {thin }} h_{\text {thin }}\right) \cdot \exp \left(-C\left(1-a_{\text {thick }}-a_{\text {thin }}\right)\right)$.

See Table 1 for the parameters $P^{*}$ and $C$. Grid-averaged seaice velocities (even without thick ice) were calculated using Hunke and Dukowicz's (1997) rheology equations and were used for estimating the advection of both thick and thin ice.

We calculated local changes in thin-ice volume at each grid point from the thin-ice thickness and area-fraction data at both the previous and present time steps and the advection effect (Advec) and diffusion effect (Diff) as

$\Delta\left(a_{\text {thin }} h_{\text {thin }}\right)=\left[a_{\text {thin }} h_{\text {thin }}\right]^{\text {present }}-\left[a_{\text {thin }} h_{\text {thin }}\right]^{\text {previous }}-$ Advec - Diff,

where present and previous indicate time steps. We used the multidimensional positive definite advection transport algorithm (Smolarkiewicz 1984) to calculate the advection and diffusion terms from the grid-averaged sea-ice velocities, in the same way as for the thick ice. When $\Delta\left(a_{t h i n} h_{t h i n}\right)$ is positive, new thin ice is created locally. In this case, the freshwater content, latent heat of melting, and the salt equivalent of this sea-ice volume in the topmost layer of the ocean are reduced. The salinity of the thin ice was set to 
(a) athin (Sep 1, 2002)

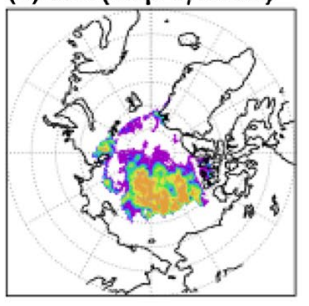

(e) Hi diff (Sep 1, 2002)

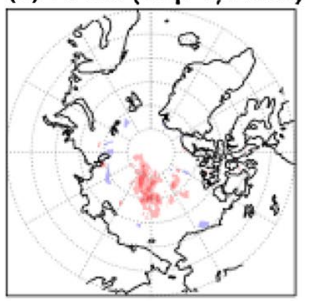

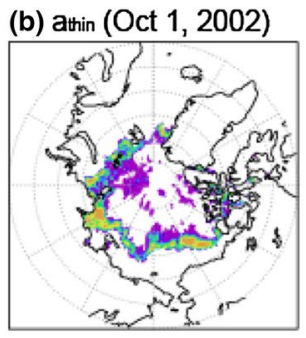

(f) $\mathrm{Hi}$ diff (Oct 1, 2002)

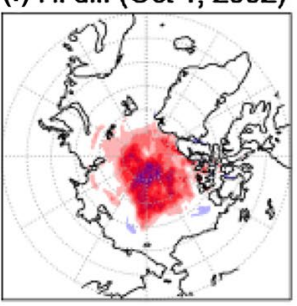

(c) attin (Nov 1, 2002)

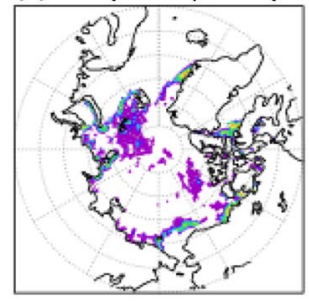

(g) Hi diff (Nov 1, 2002)

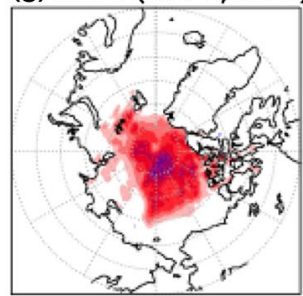

(d) athin (Dec 1, 2002)

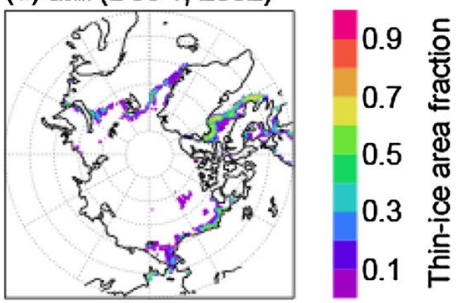

(h) Hi diff (Dec 1, 2002)

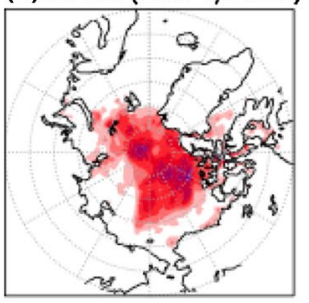

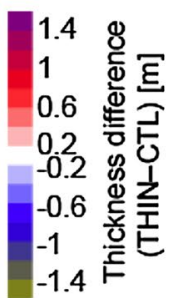

Fig. 3 Distributions of thin-ice area fraction (a-d) and differences in sea-ice thickness between the CTL and THIN experiments (e-h). a, e September 01, b, f October 01, c, $\mathbf{g}$ November 01, and d, h December 01, 2002

10.0, according to research by Cavalieri and Martin (1994). When $\Delta\left(a_{\text {thin }} h_{\text {thin }}\right)$ is negative, on the other hand, thin ice develops (thickens) and becomes thick ice. If the thinnest thick ice is category 1 within the grid, then the area fraction of this category is increased by $\Delta a_{1}=-\Delta\left(a_{\text {thin }} h_{\text {thin }}\right) / h_{1}$ while maintaining its thickness, but the snow thickness of the category 1 ice is reduced to conserve volume. Because the heat capacity of the thick ice is considered by the model, the equivalent heat to reduce the thin-ice temperature of the sea-surface freezing point to the category 1 ice temperature for the added volume is added to the topmost ocean layer. If no category 1 ice exists, then category 1 thick ice with volume $-\Delta\left(a_{\text {thin }} h_{\text {thin }}\right)$ is created with a minimum thickness of $0.1 \mathrm{~m}$ and the sea-surface freezing-point temperature. If the open-water fraction is not large enough to accommodate the new category 1 ice fraction, the part remaining is partitioned among the thickness categories according to their area-fraction ratios [as per Eqs. (6)-(8)]. In addition, because salinity of thick ice is lower than that of thin ice, salt corresponding to the ice-volume change of $-\Delta\left(a_{t h i n} h_{t h i n}\right)$ is added to the topmost ocean layer. Thus, the total amounts of heat, freshwater, and salt within the ocean-thick ice-thin ice system are conserved. Note that these calculations assume that the changes are due to freezing ice only, because thin ice produced by melting of thick ice has been removed from the thin-ice data.

In grids containing thin ice, MGDSST sea-ice-concentration data were not assimilated in order to avoid problems from inconsistencies across datasets.

\section{Results}

The impact of the inclusion of thin-ice data was investigated by comparing the results of the CTL and THIN experiments. Figure 3 shows the time evolution (in 2002) of the thin-ice area fractions input to the model in the THIN experiment (Fig. 3a-d), and the differences in the grid-averaged sea-ice thickness between the CTL and THIN experiment results (Fig. 3e-h). Thin sea ice first appeared at the end of August in the Pacific section of the Central Arctic, and by September 1, a large part of the Central Arctic was covered by thin ice with area fractions up to 0.7 (Fig. 3a). Most original data from the rim of the ice-covered area were removed by the preprocessing described in Sect. 3.1. As of October 1, the thin-ice area extended toward lower latitudes, whereas in the central part it had decreased (Fig. 3b). As of November 1, the total thin-ice area had decreased (Fig. 2a), and thin ice was confined mostly to the edges of thick-ice areas (Fig. 3c). By December 1, thin ice remained ice-area margins, which had gradually spread to include parts of the Bering Sea and Baffin Bay (Fig. 3d).

The thickness differences (THIN-CTL) at first increased in the Central Arctic (Fig. 3e) and then, as winter approached, the increased differences extended to the seas that are marginal to the Arctic Ocean (Fig. 3f-h). Although the grid-averaged values for both the thin- and thick-ice thicknesses $\left(\sum_{n=1}^{N_{c}} a_{n} h_{n}+a_{\text {thin }} h_{\text {thin }}\right.$ for the THIN case) were used to calculate the thickness differences, the direct contribution of the thin-ice thickness (up to $0.1 \mathrm{~m}$ ) to these values is relatively small. Hence, we infer that the increases in total thickness in the THIN experiment indicate that sea-ice production was enhanced by the presence of the thin ice as follows. Under freezing conditions, thick ice is formed and 
covers the ocean surface in the CTL experiment, whereas the presence of thin ice restricts the extent of the thick-ice cover in the THIN experiment (Fig. 1a). Greater heat exchange between the atmosphere and ocean, leading to enhanced seaice production, was expected in the latter case. An example of the thickness-distribution difference between the CTL and THIN experiments in the early stage of freezing (November 01,2002 ) and the corresponding ice distributions is shown in Figs. 1b, 3c, g. The modeled thick ice of $0.1-0.16 \mathrm{~m}$ thick (just above the minimum value of $0.1 \mathrm{~m}$ ) was much reduced from the CTL to the THIN experiments, resulting from the thin-ice inclusion.

We compared satellite-derived sea-ice-thickness distributions during the periods of several ICESat campaigns (Yi and Zwally 2009) with the distributions based on our CTL and THIN experiments to validate our results, as described above and as shown in Figs. 4 and 5. On the basis of work by Kwok and Cunningham (2008), we assumed the uncertainty of the observational thickness data to be on the order of $\pm 0.5 \mathrm{~m}$.

In the Canadian Archipelago and the region north of Greenland, the observational data show relatively thick sea ice ( $>4 \mathrm{~m}$ ) during most of the campaign periods (Figs. 4 , 5). This thickness was greatly underestimated in the CTL experiment, whereas the THIN experiment reproduced the relatively thick sea ice in those areas. Too, the relatively thin sea ice observed during the on07 period (Fig. 4o) and the fm08 period (Fig. 5o) in those areas, compared with earlier periods, was also reproduced by the THIN experiment (Figs. 4n, 5n, respectively).

Ice thickness in the Central Arctic, which was largely occupied by sea ice thicker than $1.5 \mathrm{~m}$ according to the observational data, particularly in the Atlantic section, was also underestimated in the CTL experiment, especially during October-November. Thicker sea ice was reproduced in the THIN experiment, although that simulated during the fm06 period (Fig. 5h) and fm08 period (Fig. 5n) appears to be too thick relative to the observational data.

In the coastal regions of the Pacific section, areas of relatively thick sea ice, possibly associated with high production at coastal polynyas (e.g., Cavalieri and Martin 1994), were sometimes observed during winter (e.g., Fig. 4f). The results of the THIN experiment (e.g., Fig. 4e) were closer to the observational data in this respect than that of the CTL experiment (e.g., Fig. 4d). However, the presence of a block of rather thick sea ice ( $>4 \mathrm{~m}$ thick) in the Pacific section during 2006-2007 as simulated in the THIN experiment (Figs. 4h, $\mathrm{k}, 5 \mathrm{~h}, \mathrm{k}$ ) suggests that some processes (e.g., ice-albedo feedback) that effectively thin the sea ice are missing in our model, particularly given that a thinner but morphologically similar ice block was seen in the observational data (e.g., Fig. 4l) and relatively thick sea ice was estimated along the Canadian coast in 2006 (Maslanik et al. 2007).
The root mean square differences (RMSDs) of the THIN experiment results relative to the observed thicknesses were generally smaller than those of the CTL experiment results for both winter and summer periods (Fig. 6). In particular, the RMSDs for areas north of Greenland and the Canadian Archipelago and in the Atlantic section of the Central Arctic seen in the CTL experiment were much larger than in the THIN case. However, THIN experiment RMSDs relative to the observational data were high in some regions of the Pacific section (e.g., Fig. 6d), which we attribute to the above-mentioned rather thick sea-ice block simulated in 2006-2007. Nevertheless, this generally enhanced reproduction of the sea-ice-thickness distribution by the THIN experiment supports our finding that the incorporation of thin-ice data improves the reproduction of sea-ice volume compared with the CTL experiment as further discussed below.

Time series of sea-ice area and volume for the Arctic Ocean are shown in Fig. 7. In the THIN experiment, the seaice area was larger than in the CTL experiment during the whole simulation period (Fig. 7a). The difference increased by as much as $1 \times 10^{6} \mathrm{~km}^{2}$ in autumn of each year, and this increase is mostly attributable to an increase in the thin-ice area (Fig. 2a). The difference did not disappear in summer, however, even though thin ice (as we defined thin ice to be only actively freezing ice) was not present then. The persistence of the difference in summer likely reflects the greater thickness of sea ice in the THIN experiment, which allowed it to persist over a wider area in the melting season. Summertime area differences between the two experiments were obtained mainly in the marginal ice zones of the Atlantic section which is in the downstream direction of sea-ice flow in the Arctic Ocean.

In the years following 2003, which, in the THIN experiment, had a rather stable seasonal cycle after an initial increase, the sea-ice volume was larger in the THIN experiment than in the CTL experiment by $5 \times 10^{3}-10 \times 10^{3} \mathrm{~km}^{3}$ (Fig. 7b). The volume difference (THIN-CTL, the green line) decreased slightly in summer, but it largely persisted throughout the melting season. As a result of the enhancement of both sea-ice formation and melting, the amplitude of the seasonal cycle in the THIN experiment increased by about $2 \times 10^{3} \mathrm{~km}^{3}$ compared with that in the CTL experiment.

Comparison of the distributions of annual sea-ice production between the two experiments (Fig. 8a-c) shows that in the THIN experiment it was mostly higher than in the CTL experiment. Differences between the experiments (THIN-CTL) were broadly positive over the Arctic Ocean with larger values in coastal regions (Fig. 8c). Thus, the high sea-ice production values in marginal ice zones and polynyas as described in previous studies (e.g., Tamura and Ohshima 2011; Iwamoto et al. 2014), were clearly represented in the THIN experiment. The THIN experiment also reproduced 
Fig. 4 Sea-ice thickness distributions in the Arctic Ocean from CTL and THIN experiments and from Ice, Cloud, and Land Elevation Satellite (ICESat) observational data (Yi and Zwally 2009) for the October-November campaign periods: October 24-November 18, 2003 (on03), October 03-November 08, 2004 (on04), October 22-November 23, 2005 (on05), October 25-November 25, 2006 (on06), and October 02-November 05, 2007 (on07). Equivalent grid-averaged thickness values $\left(\sum_{n=1}^{N_{c}} a_{n} h_{n}\right.$ for $\mathrm{CTL}$ and $\sum_{n=1}^{N_{c}} a_{n} h_{n}+a_{\text {thin }} h_{\text {thin }}$ for THIN) were plotted for our experiments. Thick blobs (see text) were indicated by red arrows in $\mathbf{h}, \mathbf{k}, \mathbf{l}$, and $\mathbf{n}$. See also Fig. S2 for the ice thickness differences for these periods (a) $\mathrm{Hi}($ on03) CTL

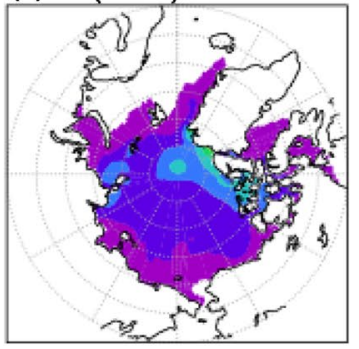

(d) $\mathrm{Hi}($ on04) CTL

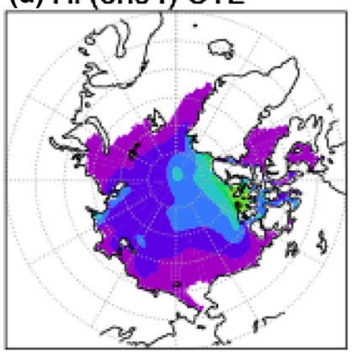

(g) $\mathrm{Hi}$ (on05) CTL

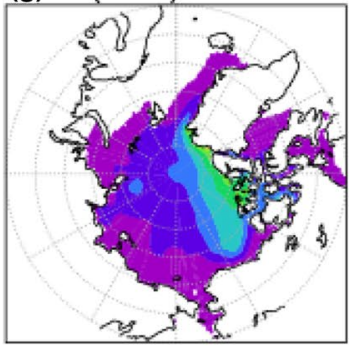

(j) $\mathrm{Hi}$ (on06) $\mathrm{CTL}$

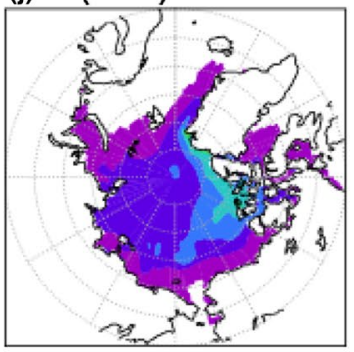

(m) $\mathrm{Hi}$ (on07) CTL

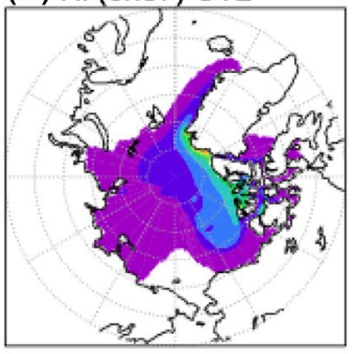

(b) $\mathrm{Hi}$ (on03) THIN

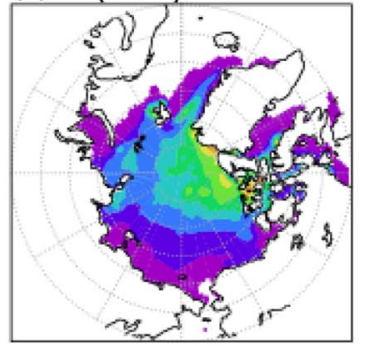

(e) Hi (on04) THIN

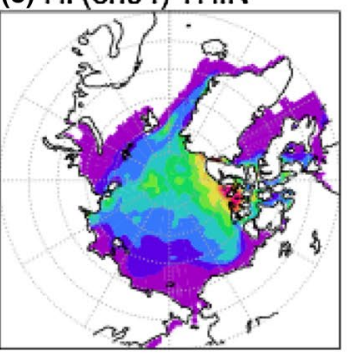

(h) $\mathrm{Hi}$ (on05) THIN

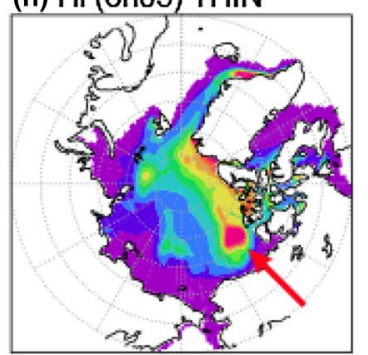

(k) $\mathrm{Hi}$ (on06) THIN

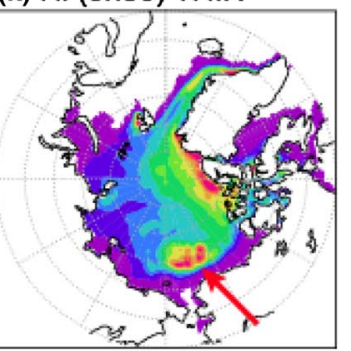

(n) $\mathrm{Hi}$ (on07) THIN

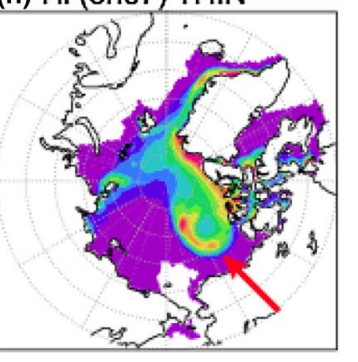

(c) Hi (on03) ICESat

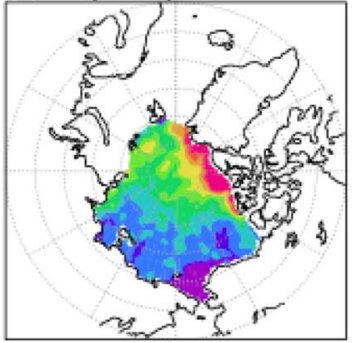

(f) $\mathrm{Hi}$ (on04) ICESat

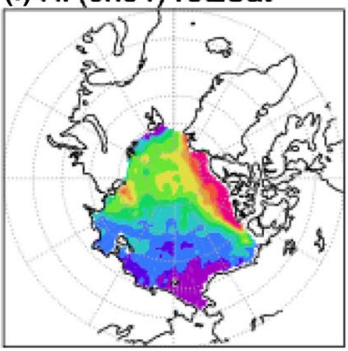

(i) $\mathrm{Hi}$ (on05) ICESat

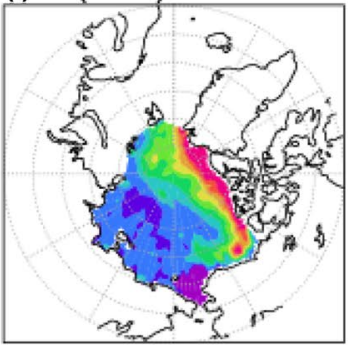

(I) Hi (on06) ICESat

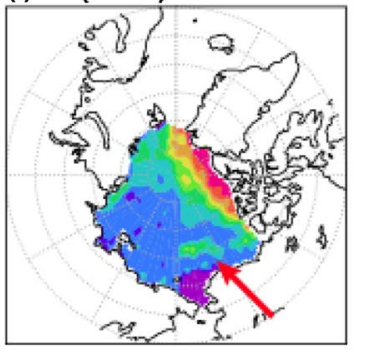

(o) Hi (on07) ICESat

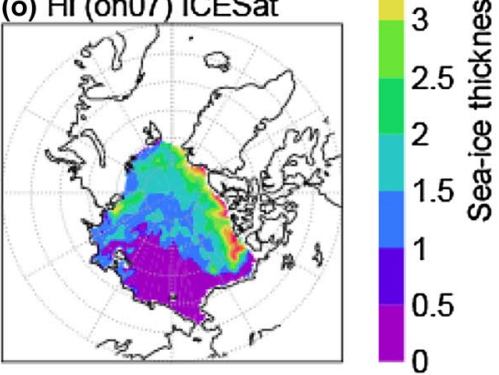

high production values confined to coastal regions of the Bering Sea (e.g., Stringer and Groves 1991), although production in those regions might be overestimated by our model owing to its coarse resolution.
In contrast to sea-ice production, sea-ice melting was lower in the Central Arctic and north of the Canadian Archipelago in the THIN than in the CTL experiment (Fig. 8f). This result can be attributed to the increased thicknesses simulated in these regions in the THIN experiment (Figs. 4, 
Fig. 5 Sea-ice thickness distributions in the Arctic Ocean from CTL and THIN experiments and from Ice, Cloud, and Land Elevation Satellite (ICESat) observational data (Yi and Zwally 2009) for the FebruaryApril campaign periods: February 17-March 21, 2004 (fm04), February 17-March 24, 2005 (fm05), February 22-March 27, 2006 (fm06), March 12-April 14, 2007 (ma07), and February 17-March 21, 2008 (fm08). Equivalent grid-averaged thickness values $\left(\sum_{n=1}^{N_{c}} a_{n} h_{n}\right.$ for CTL and $\sum_{n=1}^{N_{c}} a_{n} h_{n}+a_{\text {thin }} h_{\text {thin }}$ for THIN) were plotted for our experiments. See also Fig. S2 for the ice thickness differences for these periods (a) $\mathrm{Hi}(\mathrm{fm04}) \mathrm{CTL}$

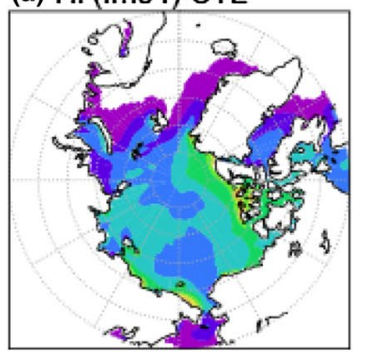

(d) $\mathrm{Hi}(\mathrm{fm} 05) \mathrm{CTL}$

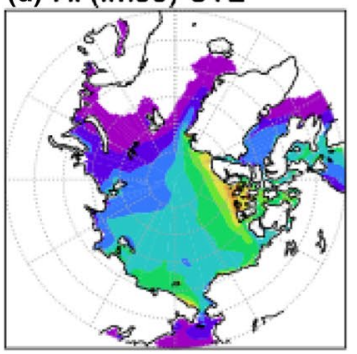

(g) $\mathrm{Hi}(\mathrm{fm} 06) \mathrm{CTL}$

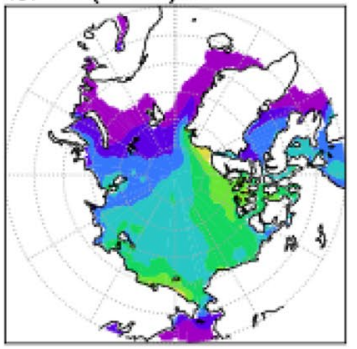

(j) $\mathrm{Hi}(\mathrm{ma07}) \mathrm{CTL}$

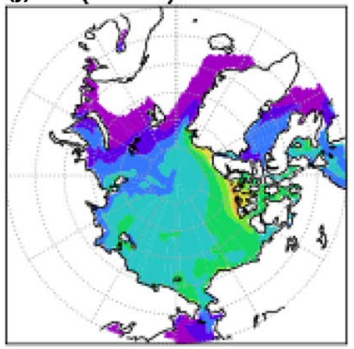

(m) $\mathrm{Hi}(\mathrm{fm08}) \mathrm{CTL}$

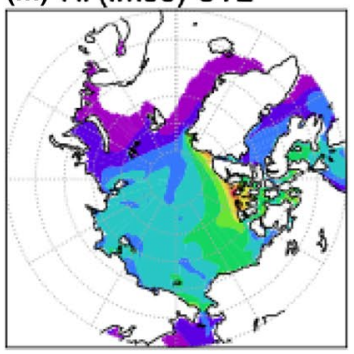

(b) Hi (fm04) THIN

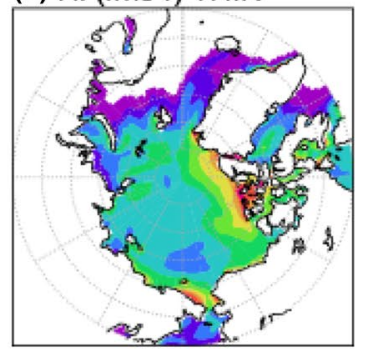

(e) $\mathrm{Hi}(\mathrm{fm05}) \mathrm{THIN}$

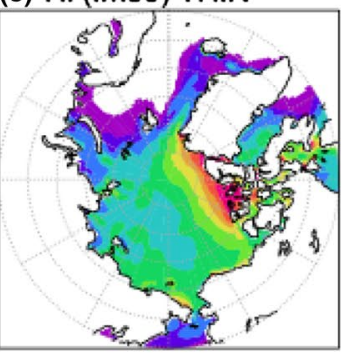

(h) Hi (fm06) THIN

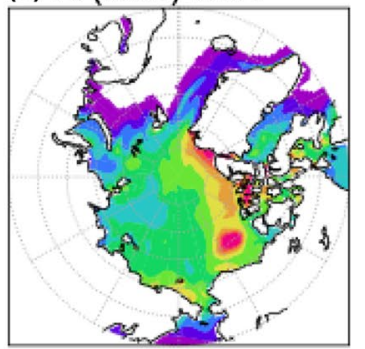

t(k)Hi (ma07) THIN

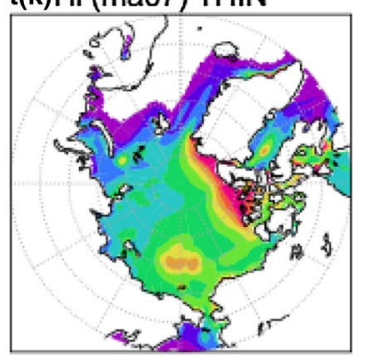

(n) $\mathrm{Hi}$ (fm08) THIN

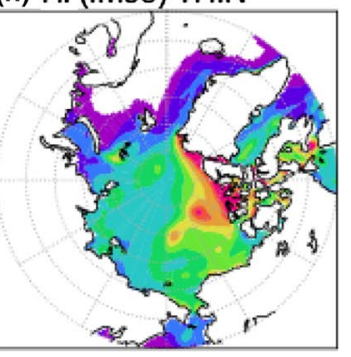

(c) Hi (fm04) ICESat

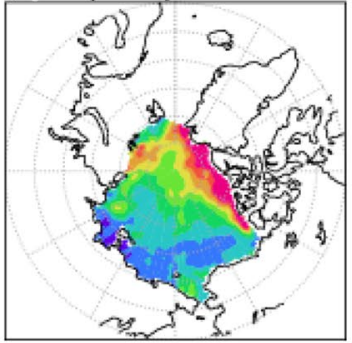

(f) Hi (fm05) ICESat

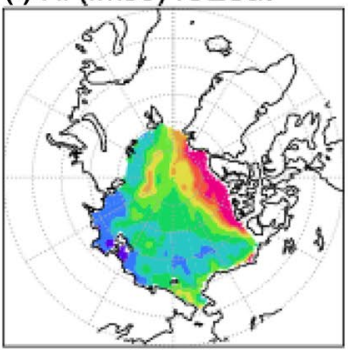

(i) $\mathrm{Hi}(\mathrm{fm06})$ ICESat

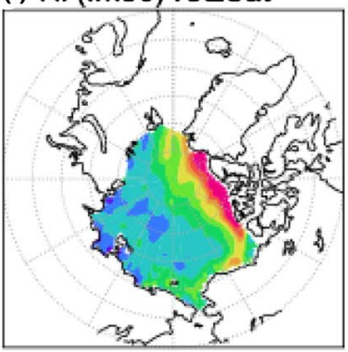

(I) $\mathrm{Hi}(\mathrm{ma07})$ ICESat

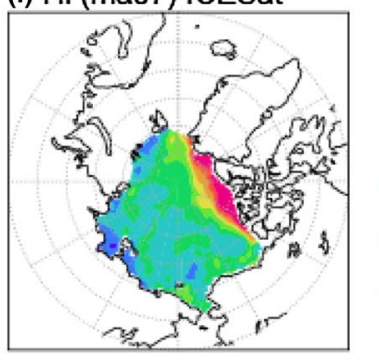

(o) $\mathrm{Hi}$ (fm08) ICESat

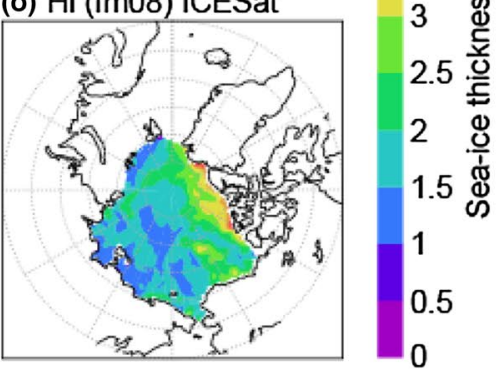

5), as discussed above. In contrast, in most marginal ice zones, sea-ice melting was increased in the THIN experiment, but these increases in sea-ice melting were not confined to coastal polynya regions. Consistent with the enhanced seasonal cycle of total sea-ice volume resulting from the incorporation of thin-ice data (Fig. 7b), annual seaice production and melting were both greater overall in the THIN experiment than in the CTL experiment.

Changes in sea-ice production and melting can affect salinity in the ocean surface layer. Differences in salinity 
(a) Hi RMSD (on) CTL

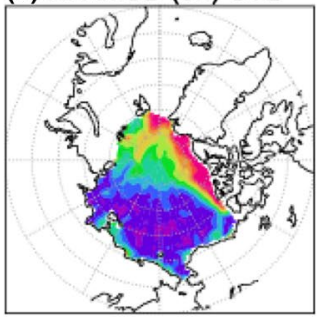

(b) Hi RMSD (on) THIN

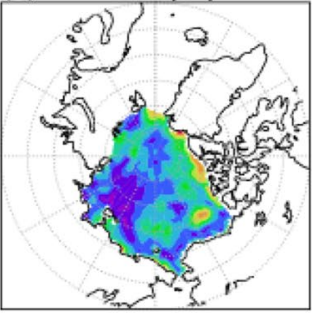

(c) Hi RMSD (fm) CTL

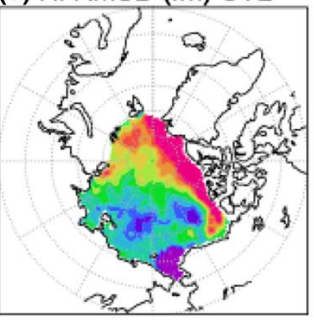

(d) Hi RMSD (fm) THIN

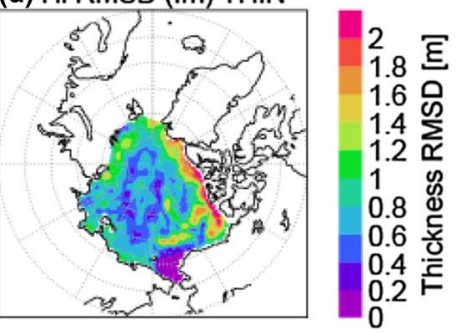

Fig. 6 Distributions of the RMSDs between experimental results (a, c CTL; b, d THIN) and observational data (Figs. 4 and 5) for sea-ice thickness for October-November periods (on03, on04, on05, on06,

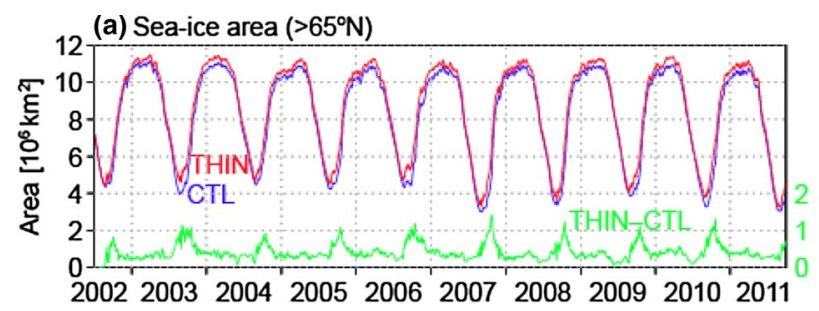

(b) Sea-ice volume $\left(>65^{\circ} \mathrm{N}\right)$

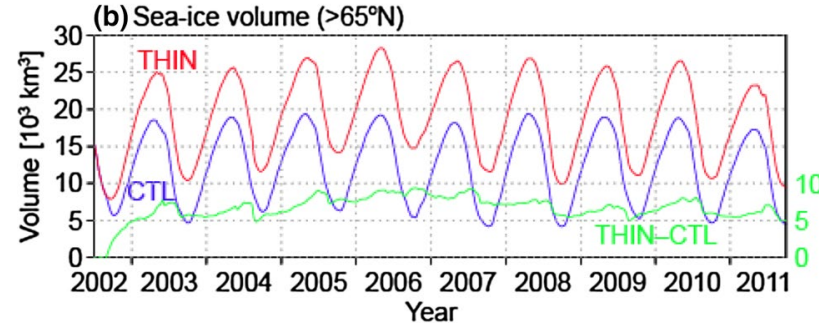

Fig. 7 Time series of sea-ice area (a) and volume (b) for the Arctic Ocean (north of $65^{\circ} \mathrm{N}$ ). Blue and red lines indicate the results from the CTL and THIN experiments, and the green lines indicate the differences between the experiments (THIN-CTL; right-side vertical axis). Thin-ice values are included for the plots of the THIN experiment and on07) and for February-March and March-April periods (fm04, fm05, fm06, ma07, and fm08)

were positive (greater salinity in the THIN experiment) at 10-m depth in the Central Arctic and around the Canadian Archipelago in both September and March (Fig. 9a, $\mathrm{b}$, respectively). The positive differences in these regions are due to both increases in production and decreases in melting (Fig. 8c, f). In some marginal seas elsewhere, differences were predominantly negative in September, whereas there were positive differences in the Beaufort Sea and the northeastern Barents Sea in March. Generally speaking, surface salinity would be more influenced by melting, which occurs when the surface mixed layer is relatively shallow, such as in September, compared with production, which occurs when the surface mixed layer is relatively deep (as discussed below). On the other hand, the positive wintertime (March) differences can be attributed to enhanced production in polynyas above the Alaskan and Canadian continental shelves and along the coasts of Novaya Zemlya and Franz Josef Land (Fig. 8c).

At 100-m depth, salinity differences were positive in the Central Arctic and the Beaufort Sea, whereas they were negative around the Barents Sea and Fram Strait (Fig. 9c). The seasonal variation in these differences was rather small at
Fig. 8 Distributions of annual sea-ice production $(\mathbf{a}-\mathbf{c})$ and melting $(\mathbf{d}-\mathbf{f})$ values, averaged over the period 2003-2010. a, d CTL, b, e THIN, and $\mathbf{c}, \mathbf{f}$ difference between the experiments (THIN-CTL) (a) Production CTL

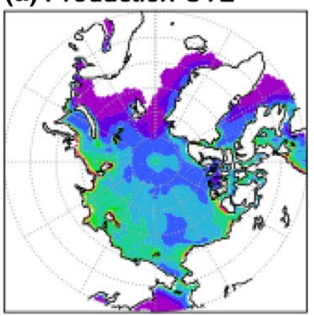

(d) Melting CTL

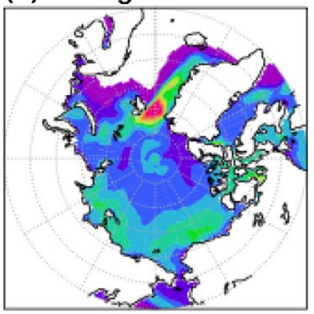

(b) Production THIN

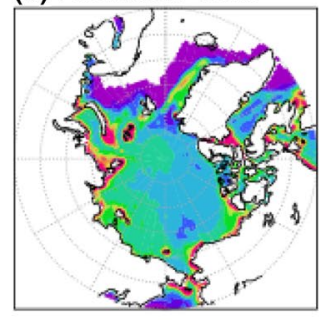

(e) Melting THIN

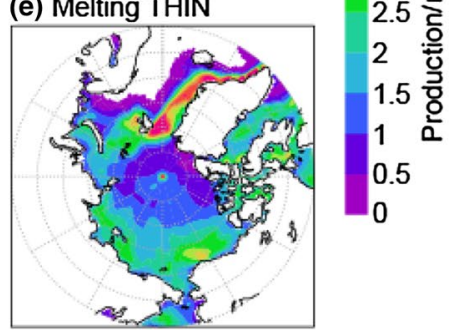

(c) Production difference

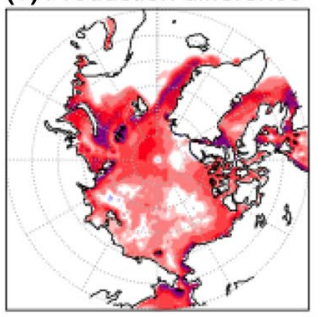

(f) Melting difference

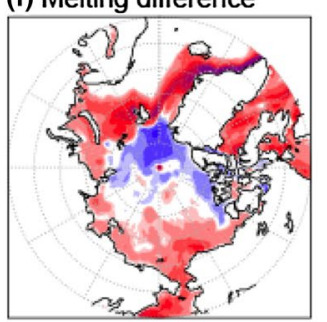

2.5 2 䌿 1.5 트 0.5 궁 0.5 $0.1 \mathrm{z}$ -0.1 폰 -0.2 E $-0.5 \&$ $-1.5$ $-1.5 \frac{\mathrm{d}}{\mathrm{d}}$ $-2.50$ $-3.5$ 
(a) Salinity $10 \mathrm{~m}$ Sep

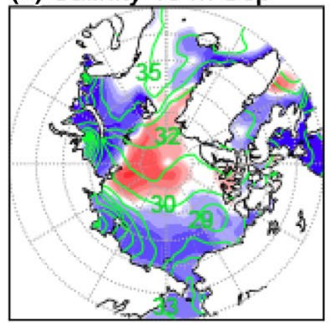

(b) Salinity $10 \mathrm{~m}$ Mar

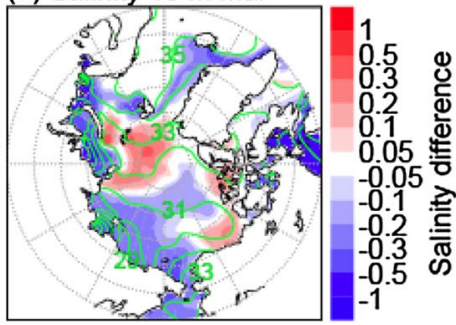

(c) Salinity $100 \mathrm{~m}$ annual

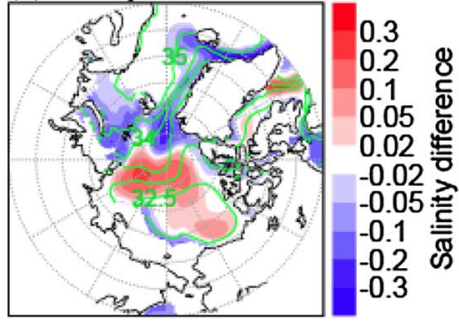

Fig. 9 Distributions of salinity differences between the CTL and THIN experiments (THIN-CTL) for a September and b March at $10-\mathrm{m}$ depth and for $\mathbf{c}$ annual mean at 100-m depth. Green contours indicate the salinities in the CTL experiment with contour intervals of 1 for (a and $\mathbf{b}$ ) and 0.5 for (c). Values were calculated from monthly climatology data during the period January 2003-September 2011 this depth. The positive differences can be attributed largely to enhanced sea-ice production in these regions (Fig. 8c). In contrast to salinity at the surface, salinity at $100-\mathrm{m}$ depth is influenced less by melting than by sea-ice production, which occurs when the surface mixed layer is relatively deep. An example of the relationship between MLD and salinity along $145^{\circ} \mathrm{W}$ (i.e., across the large salinity differences in the Beaufort Sea, shown in Fig. 9c) is shown in Fig. 10. Here, MLD is defined as the depth at which potential density exceeds the $10-\mathrm{m}$ depth value by $0.03 \mathrm{~kg} \mathrm{~m}^{-3}$ (e.g., Toyoda et al. 2017). MLD values were intermittently relatively large in the Beaufort Sea (about $70^{\circ}-75^{\circ} \mathrm{N}$ ), and they were generally larger in the THIN experiment than in the CTL experiment (Fig. $10 \mathrm{a}, \mathrm{b})$. At a typical point $\left(145^{\circ} \mathrm{W}, 72^{\circ} \mathrm{N}\right)$, relatively high salinity (e.g., > 32) was distributed rather uniformly within the relatively deep mixed layer (Fig. 10d), and large salinity differences were generated concurrently at these greater depths (Fig. 10e). In contrast, lower surface-layer salinities (Fig. 10d) and concurrent negative salinity differences (Fig. 10e), affected by sea-ice melting (Fig. 10c), were generally associated with a relatively shallow mixed layer, with a thickness of a few tens of meters; as a result, positive salinity differences were maintained in the subsurface layer until 2008 (Fig. 10e). It is interesting that such a deep mixed layer did not develop after 2008, and the variability in the surface-layer salinity drastically changed around 2007-2008. Giles et al. (2012) reported a positive trend of freshwater content in the Beaufort Gyre between 2002 and 2010 mainly due to the wind stress curl anomaly. Our results were qualitatively consistent with the previous study and suggest the possible importance of including thin-ice information in simulating the freshwater-content variability in the Beaufort Gyre. The positive salinity differences at 100-m depth in the Beaufort Sea (e.g., at $72^{\circ} \mathrm{N}$ ) (Fig. 9c) were generated by the above sea-ice production process with the greater MLDs. On the other hand, the positive differences at 100-m depth in the northern Canada Basin are apparently not directly attributable to changes in MLD but were affected by a horizontal
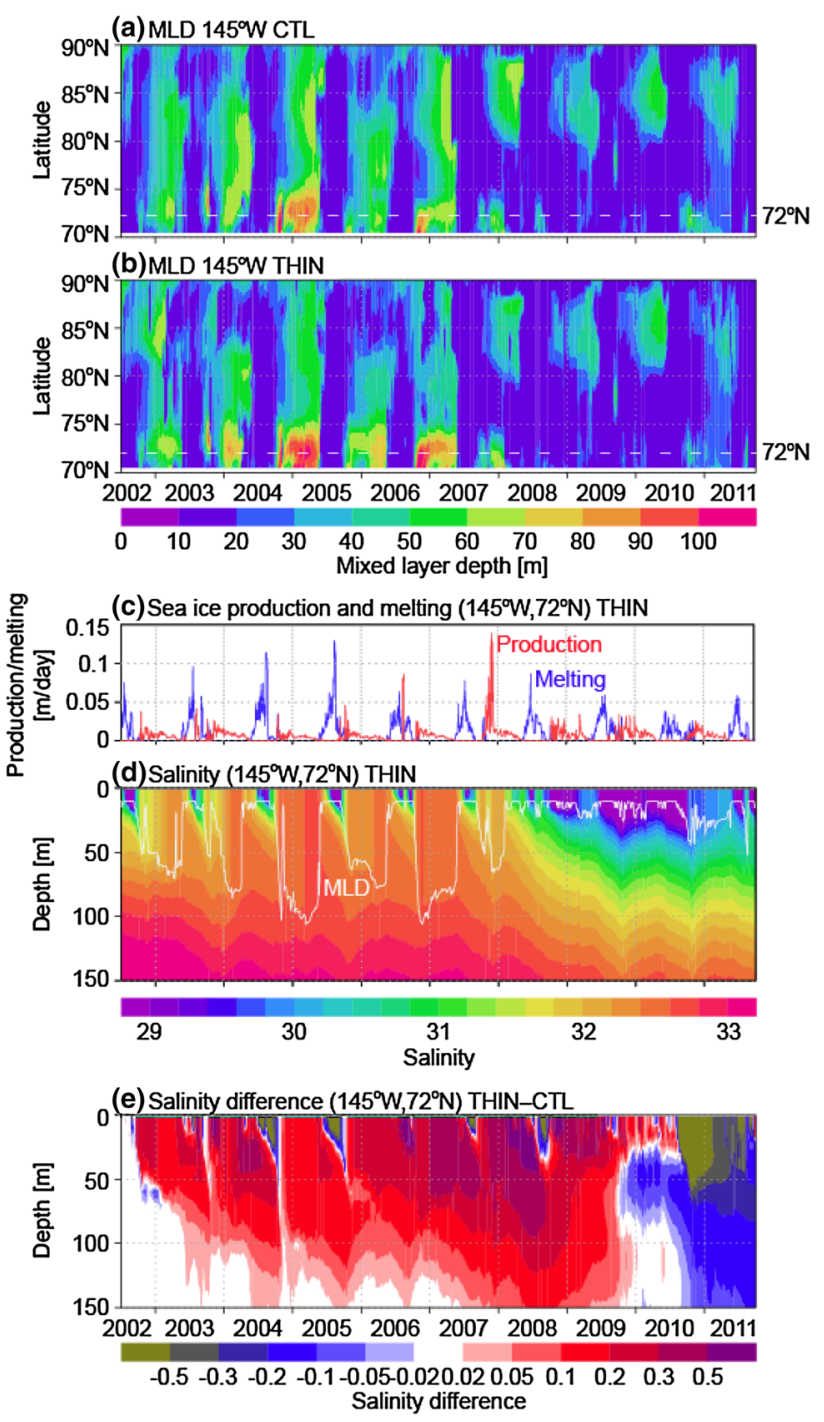

Fig. 10 a, b Time evolution of the MLDs along the $145^{\circ} \mathrm{W}$ line from the CTL and THIN experiments. c-e Time evolution of sea-ice production (red), melting (blue), MLD (white, in d), vertical profiles of salinity (THIN), and salinity difference (THIN-CTL) in the Beaufort Sea $\left(145^{\circ} \mathrm{W}, 72^{\circ} \mathrm{N}\right)$ 


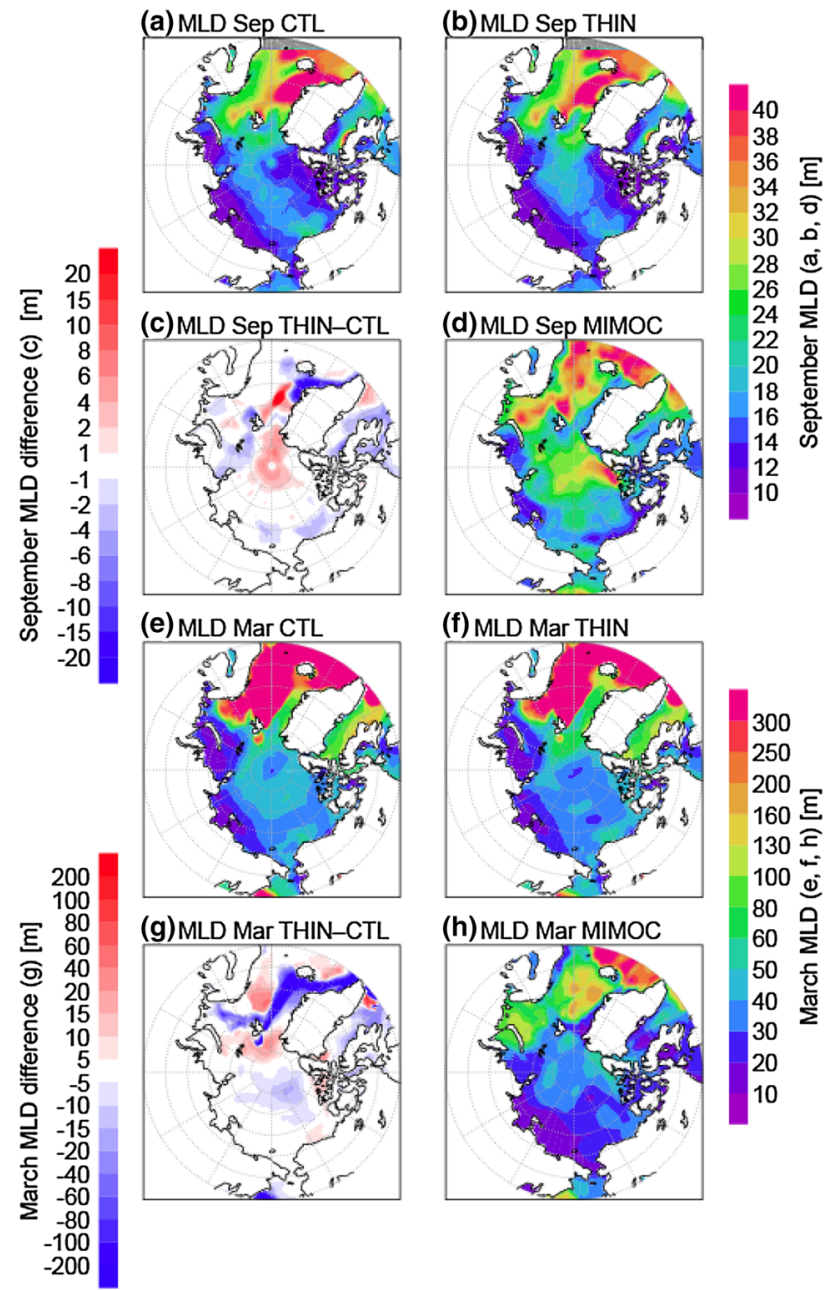

Fig. 11 MLD-distribution climatology data for September (a-d) and March (e-h). a, e CTL experiment. b, f THIN experiment. c, $\mathbf{g}$ Difference between the two experiments. d, h MIMOC data. MLD monthly climatology data in the experiments were calculated from daily mean outputs of temperature and salinity fields (from daily MLDs) for the period January 2003-September 2011

process, because the mixed layer did not reach 100-m depth in the Canada Basin north of $75^{\circ} \mathrm{N}$ (Fig. 10b).

In the Atlantic section, negative salinity differences at 100-m depth (Fig. 9c) emerged where relatively fresh Arctic surface water confronted salty Atlantic Water (corresponding to salinity of 33.5-35). Eastward velocity in the ocean surface layer increases in the THIN experiment relative to the CTL experiment to the north of Greenland (not shown) were possibly responsible for the large salinity differences in the Atlantic section. However, the resolution of our system is not high enough to further discuss the changes in frontal structures.

MLD is the bulk variable essential for surface stratification, and salinity distribution is important in defining the
MLD for the Arctic Ocean (e.g., Tomczak and Godfrey 1994). We therefore compared the MLD-distribution climatologies of the CTL and THIN experiments with that of the observational MIMOC dataset (Schmidtko et al. 2013), which is based on available temperature and salinity profiles, including Ice-Tethered Profiler data from under the sea ice in the Arctic Ocean (Fig. 11).

The September MLDs for the Central Arctic, 20-30 m (Fig. 11d), were underestimated in both the CTL and THIN experiments (Fig. 11a, b, respectively) relative to the MIMOC observational data. Because the estimated MLDs were greater in the THIN experiment than in the CTL experiment (Fig. 11c), the estimation of MLD was improved to some extent by the incorporation of thin-ice data. In detail, because the THIN MLDs in the southern Beaufort Sea and around the Svalbard Islands, Franz Josef Land, and Severnaya Zemlya were reduced relative to the CTL MLDs (Fig. 11c), it is difficult to detect an improvement with respect to the MIMOC data in the THIN experiment results.

The observed March climatological MLDs were mostly 30-40 m for the Central Arctic (Fig. 11h). The CTL experiment overestimated the MLDs relative to observational data by about $10 \mathrm{~m}$ (Fig. 11e), whereas the MLDs simulated by the THIN experiment were relatively shallower (i.e., closer to the MIMOC data) in the Pacific section of the Central Arctic, although they were thicker north of the Fram Strait (Fig. 11f). These MLD results are consistent with the salinity differences (THIN-CTL) (Fig. 9), which were negative at $10-\mathrm{m}$ depth and positive at 100-m depth for the Pacific section and were positive at $10-\mathrm{m}$ depth and negative at $100-\mathrm{m}$ depth north of the Fram Strait.

To evaluate our salinity results, we used CTD observational data $(247,262,100$, and 178 salinity profiles) obtained during Arctic cruises MR04-05, MR08-04, MR09-03, and MR10-05 of the R/V Mirai, respectively. We compared the individual profiles with the corresponding daily mean outputs of the experiments and calculated RMSDs within each model grid and over each cruise period. RMSDs were 2-4 near the surface and decreased with depth in the CTL experiment (Fig. 12). RMSDs were generally smaller in the THIN experiment, and the RMSD differences between the two experiments were mostly in the surface layer. Hence, we focus here on the RMSD differences between the experiments at 10-m depth in the surface layer.

In summer-fall 2004 (MR04-05 cruise), RMSD decreases from the CTL to the THIN experiments were widely distributed in the western Beaufort Sea and northern Chukchi Sea (Fig. 12b). The 10-m salinities decreased by $0.5-2$ from the CTL to the THIN experiments for these regions (Fig. 12c), and thus the reproduction of the relatively fresh surface water was improved. This possibly resulted from 
Fig. 12 a, d, g, j Vertical distributions of the salinity RMSDs of the CTL and THIN experiments from the conductivity-temperature-depth (CTD) observations for each cruise of the R/V Mirai. b, e, h, k Horizontal distributions of the salinity RMSD change from the CTL to THIN experiments at $10-\mathrm{m}$ depth for the cruise periods. c, f, $\mathbf{i}, \mathbf{l}$ Horizontal distributions at $10-\mathrm{m}$ depth of salinity in the CTL experiment (contour) and the salinity difference between the CTL and THIN experiments (color shading) averaged over the cruise periods. Color shading information of $\mathbf{b}, \mathbf{e}, \mathbf{h}$, and $\mathbf{k}$ and $\mathbf{c}, \mathbf{f}, \mathbf{i}$, and $\mathbf{l}$ are presented in the left and right of the figures, respectively. Time periods of the CTD observations on the R/V Mirai cruises were September 03-October 09, 2004 (a-c); August 28-October 06, 2008 (d-f); September 10-October 10, $2009(\mathbf{g}-\mathbf{i})$; and September 04-October 13, 2010 (j-l). For calculating the RMSDs, daily mean values from our experiments were compared with the individual CTD observations, and RMSDs within the model grids were averaged over the time periods

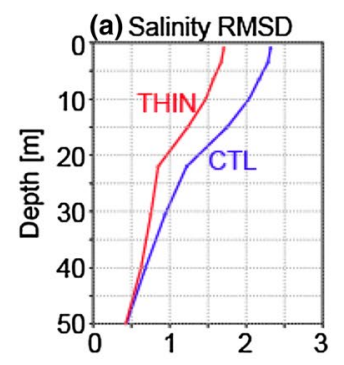

(b) RMSD change $10 \mathrm{~m}$

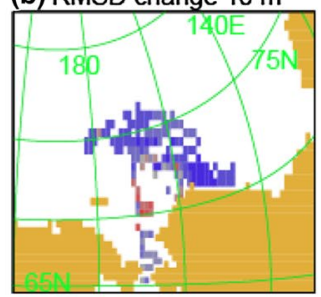

(c) Salinity $10 \mathrm{~m}$
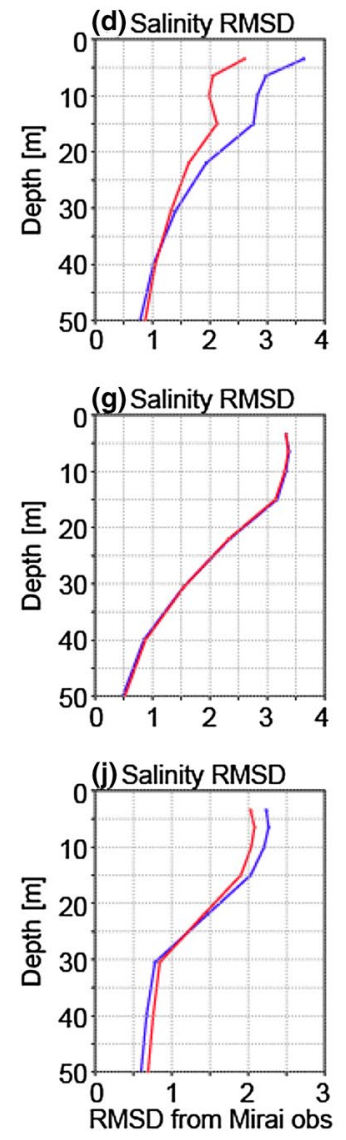

RV Mirai cruise MR04-05: Sep 3-Oct 9, 2004

(e) RMSD change $10 \mathrm{~m}$
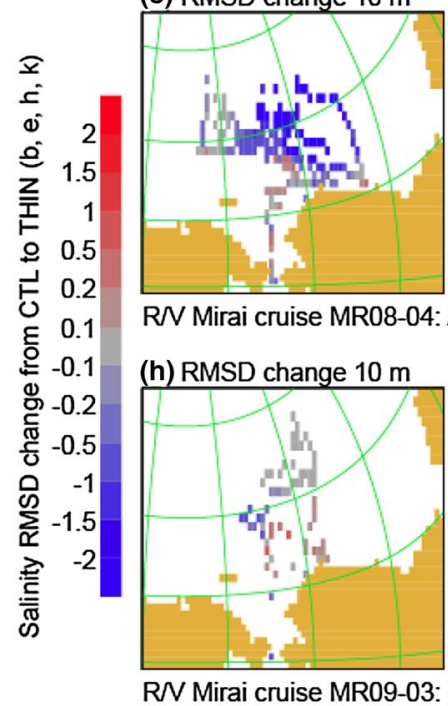

(f) Salinity $10 \mathrm{~m}$

RV Mirai cruise MR08-04: Aug 28-Oct 6, 2008

(h) RMSD change $10 \mathrm{~m}$

(i) Salinity $10 \mathrm{~m}$

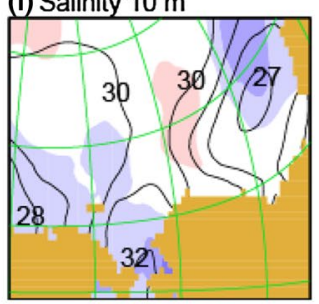

RN Mirai cruise MR09-03: Sep 10-Oct 10, 2009

(k) RMSD change $10 \mathrm{~m}$
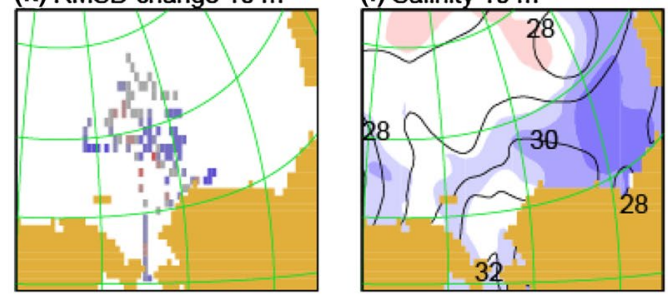

RV Mirai cruise MR10-05: Sep 4-Oct 13, 2010
(I) Salinity $10 \mathrm{~m}$ the enhanced reproduction of sea-ice melting through the incorporation of thin-ice data, as discussed above.

Similar RMSD changes and freshening from the CTL to the THIN experiments were seen in 2008 (MR08-04 cruise) (Fig. 12e, f). This cruise covered the middle of the Canada Basin, where we identified large RMSD reductions (as much as 2) that corresponded to freshening in the THIN experiment relative to the CTL experiment.

In 2009 (MR09-03 cruise), RMSD decreases from the CTL to the THIN experiments were confined to a small region in the northern Chukchi Sea (Fig. 12h); as a result, total RMSD profiles were similar in the CTL and THIN experiments, and RMSD values were relatively large (Fig. 12g). Salinity differences between the experiments during the period of this cruise were generally small in the cruise area (Fig. 12i). The enhanced melting by the incorporation of thin-ice data had only a small effect, and the large salinity biases (greater than 3 at 10-m depth) in both experiments for the year 2009 might be related to the fact that the September sea-ice extent during the 2007-2012 period was largest in 2009, even though the overall trend was decreasing (e.g., Serreze et al. 2016), but further examination of these results remains for future work.

In 2010 (MR10-05 cruise), salinity changes from the CTL to the THIN experiments were negative in the marginal seas of the Pacific section and again RMSD decreased in the surface layer (Fig. 12j-1).

During all four cruise periods, positive RMSD changes were seen in the northern Chukchi Sea, indicating that the reproduction of salinity there was worse in the THIN experiment. Because salinities in the region were generally lower 
in the THIN experiment than in the CTL experiment, the salinities observed during the cruises were high relative to the simulation results. These high salinities can be attributed to the influence of Pacific water. On the basis of CTD observations made during the Surface Heat Budget of the Arctic Ocean (SHEBA) drift experiment in 1997-1998, Shimada et al. (2001) reported isohalines of 31-32 (corresponding to Eastern Chukchi Sea Water) in the surface mixed layer above the Chukchi Plateau. Further, they showed that the bottom topography played an important role in determining Pacific water circulation in the Beaufort and Chukchi Seas. Unfortunately, the characteristic Northern Ridge and Chukchi Plateau were not well resolved in our coarse-resolution system, which may account for the low-salinity biases in our experiments.

Overall, general improvement in the surface-salinity field in the marginal ice zones suggests that the inclusion of the thin-ice information has a positive effect for representing the ocean-sea-ice fields due to the enhanced production and melting cycles of the thick sea ice.

\section{Conclusions}

We have proposed a method of incorporating thin-ice thickness data derived from satellite microwave measurements into an OGCM simulation. The thin-ice area fraction and thickness values on the model grids were calculated from the original thin-ice thickness data (Iwamoto et al. 2014) and input to the model as surface boundary conditions to constrain the evolution of the modeled sea-ice distribution. The results of experiments with and without the input of thin-ice data showed that sea-ice production was enhanced by the presence of thin ice instead of the thick ice that was modeled as developing in a short time period under freezing conditions in the baseline experiment (without the input of thinice data). The thicker sea ice resulting from the enhanced sea-ice production partly remained after the seasonal disappearance of thin ice from the Arctic Ocean. Ice thicknesses in sea-ice convergence regions such as the Canadian Archipelago were particularly impacted due to both local and remote effects via advection and ridging processes. As a result, the total sea-ice volume for the Arctic Ocean was increased by $5 \times 10^{3}-10 \times 10^{3} \mathrm{~km}^{3}$ compared with that in the baseline experiment (averaging about $57 \%$ increase in the annual mean volume). In addition, the amplitude of the seasonal cycle of sea-ice volume was increased by about $2 \times 10^{3} \mathrm{~km}^{3}$ (about $15 \%$ of the baseline-experiment value) owing to the enhancement of both sea-ice production and melting. This enhanced melting can also be attributed to the advection of the thickened ice to the marginal ice zones, where the ice melts away in summer.
In the experiment incorporating the thin-ice data, the sea-ice thickness distribution was improved with respect to the observational estimates from the ICESat measurements (Yi and Zwally 2009), particularly north of Greenland and the Canadian Archipelago and in the Atlantic section of the Central Arctic. High sea-ice production values were also reproduced in coastal polynya regions, as discussed in previous studies (e.g., Iwamoto et al. 2014).

The enhanced sea-ice production and melting in the THIN experiment affected the salinity field, which resulted in increased summertime MLDs and decreased wintertime MLDs in the Central Arctic. These THIN experiment results were more consistent with the observation-based MIMOC MLD climatology data (Schmidtko et al. 2013) than with the baseline-experiment results. The salinity changes were further evaluated by using CTD observations from R/V Mirai cruises conducted in ice-free regions of the Pacific section of the Arctic Ocean (e.g., Nishino et al. 2013). Surface salinities were decreased by the enhanced melting, and a generally improved surface-salinity field was obtained for the western Beaufort Sea and the northern Chukchi Sea.

These results suggest the importance of thin-ice processes in representing the ocean-sea-ice fields and support the effectiveness of our approach of incorporating the thin-ice information to enhance the ocean-sea-ice simulations.

In some respects, however, the reproducibility was decreased by the incorporation of thin-ice data. For example, a block of very thick ice remained without melting in the Beaufort Sea during 2006-2007. In addition, observed surface salinities in summer were lower than the simulated results even in the THIN experiment. These results suggest that parameterizations of processes (such as associated with albedo) that effectively melt thick ice are needed in the model forced by thin-ice data to improve the reproduction of the ocean-sea-ice field. Multi-layer thermodynamics should be a more appropriate option for representing thicker sea ice as implemented in recent versions of $\mathrm{CICE}^{13}$ and other sea-ice models (e.g., Rousset et al. 2015). In addition, a parameterization that distributes the brine rejected during sea-ice production directly below the surface mixed layer (e.g., Matsumura and Hasumi 2008; Nguyen et al. 2009) would improve the salinity and MLD fields. The outcropping of salty Pacific water in the surface mixed layer above the Chukchi Plateau, as captured by CTD observations (Shimada et al. 2001), was not well represented in our experiments. Thus, a model that successfully resolves the topography of Chukchi Plateau and the Northern Ridge would allow more realistic reproduction of Pacific water circulation, which also influences sea-ice melting. Also, sources of the surface freshwater have been quantified in recent years by biogeochemical tracer observations (e.g., Yamamoto-Kawai

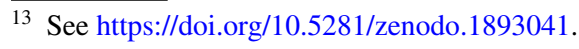


et al. 2009; Kosugi et al. 2017). These observational data are expected to be of great value for evaluating and improving the model's reproduction of surface-layer salinities.

More sophisticated incorporation of thin-ice data might be possible by a data-assimilation approach, but, in that case, thin ice would need to be (explicitly) represented in the model by a prognostic variable. Ikeda et al. (2004) improved the time evolution of the Okhotsk Sea ice distribution by introducing a $0.1-\mathrm{m}$ sea-ice thickness category as thin ice to an ocean-sea-ice simulation. (We used $0.1 \mathrm{~m}$ as the minimum thick-ice thickness in this study.) Further evaluation of simulations conducted with a prognostic thin-ice thickness variable thinner than $0.1 \mathrm{~m}$ is necessary before thin-ice data constrains the prognostic thin-ice variable through data assimilation. To do so, we should seek how to explicitly model thin ice appropriately. Existing rheology might not be suitable for ridging/rafting of thin ice. Albedo parameterization might also be improved for thin ice with ice type information. Thus, observations studies on processes associated with sea-ice formation (e.g., Ito et al. 2015) should be of great value to explicitly and appropriately model the thin ice.

It should be noted that the validated variables are also considered to vary depending on other model parameters and surface boundary conditions. For example, sea-ice thicknesses north of Greenland and the Canadian Archipelago are sensitive to the sea-ice strength parameter $P^{*}$ and the air-ice drag coefficient $C d_{a i}$ (Steele et al. 1997). Too, the vertical mixing parameterization used in a model strongly influences the MLD distribution (Komuro 2014). Nevertheless, the parameter set used in our experiments (Sect. 2) is standard among models included in recent intercomparison studies (e.g., Danabasoglu et al. 2014; Uotila et al. 2019). Also, the biases in the CTL experiment in this study (e.g., thinner sea ice and a mixed layer that is shallower in summer and deeper in winter) are seen in many existing models and reanalyses (e.g., Laxon et al. 2013; Uotila et al. 2019). These models can be expected to be similarly improved by using the method presented in this study. In cases when simulations overestimate large-scale ice volume, our approach would deteriorate the simulations. Nevertheless, since our results suggested the great influences of the thin-ice data constraint to the ocean-sea-ice fields, parameter tuning adopted in advance to the simulations would differ and might be more appropriate. In addition, rather stable seasonal cycles for both total sea-ice area and volume were achieved after initial increases (Fig. 7), which suggested that a negative feedback worked against the increasing effect of the thin-ice data incorporation. Thus, the approach would not yield an unstable increase of sea ice.

The generally positive results obtained by this study underline the great potential of satellite-derived thinice data to improve Arctic Ocean simulations when used within a dynamical model framework. Thin-ice thickness distributions have also been retrieved for the Antarctic Ocean and the Okhotsk Sea (e.g., Ohshima et al. 2016) as well as by other sensors for the Arctic Ocean (e.g., Martin et al. 2004). An enhanced thin-ice estimation algorithm that takes into account ice type has recently been proposed (Nakata et al. 2018). The effects of the incorporation of these additional data on ocean-sea-ice simulations should also be investigated, preferably with an improved OGCM as discussed above. Moreover, a comprehensive estimate of the thin-ice distribution that includes global sea-ice regions and integrates measurements from several satellites would be of great value. For such a comprehensive estimate, particularly for operational use, continuous measurements by satelliteborne passive microwave sensors are extremely important.

Acknowledgements We thank 3 anonymous reviewers and the Executive Editor of the Climate Dynamics, JC Duplessy for many of valuable comments. We are indebted to T. Kikuchi (JAMSTEC) for helping us to use the observational data of the R/V Mirai Arctic cruises. We acknowledge M. Ishii, Director-General of the Oceanography and Geochemistry Research Department of the MRI, for encouraging us to complete this study. We also thank S. T. Duhon (Rujuke Editorial Service) for her critical reading of our paper. This research was partly supported by the Japan Society for the Promotion of Science (KAKENHI Grant Number 16K17805) and by Study on Arctic Climate Predictability (Theme 5) of the Arctic Challenge for Sustainability (ArCS) project funded by the Japanese Ministry of Education, Culture, Sports, Science and Technology.

Open Access This article is distributed under the terms of the Creative Commons Attribution 4.0 International License (http://creativeco mmons.org/licenses/by/4.0/), which permits unrestricted use, distribution, and reproduction in any medium, provided you give appropriate credit to the original author(s) and the source, provide a link to the Creative Commons license, and indicate if changes were made.

\section{References}

Boyer TP, Antonov JI, Baranova OK, Coleman C, Garcia HE, Grodsky A, Johnson DR, Locarnini RA, Mishonov AV, O'Brien TD, Paver CR, Reagan JR, Seidov D, Smolyar IV, Zweng MM (2013) World Ocean Database 2013. In: Levitus S, Mishonov A (eds) NOAA Atlas NESDIS 72, p 209. https://doi.org/10.7289/v5nz85mt

Cavalieri DJ (1994) A microwave technique for mapping thin sea ice. J Geophys Res 99:12561-12572. https://doi.org/10.1029/94jc00707

Cavalieri DJ, Martin S (1994) The contribution of Alaskan, Siberian, and Canadian coastal polynyas to the cold halocline layer of the Arctic Ocean. J Geophys Res 99:18343-18362. https://doi. org/10.1029/94jc01169

Cavalieri DJ, Parkinson CL, Gloersen P, Comiso JC, Zwally HJ (1999) Deriving long-term time series of sea ice cover from satellite passive-microwave multisensor data sets. J Geophys Res 104:1580315814. https://doi.org/10.1029/1999JC900081

Chevallier M, Smith GC, Dupont F, Lemieux JF, Forget G, Fujii Y, Hernandez F, Msadek R, Peterson KA, Storto A, Toyoda T, Valdivieso M, Vernieres G, Zuo H, Balmaseda M, Chang Y-S, Ferry N, Garric G, Haines K, Keeley S, Kovach RM, Kuragano T, Masina S, Tang Y, Tsujino H, Wang X (2017) Intercomparison of the Arctic sea ice cover in global ocean sea ice reanalyses 
from the ORA-IP project. Climate Dyn 49:1107-1136. https://doi. org/10.1007/s00382-016-2985-y

CLS (2012) Ssalto/Duacs user handbook: (M)SLA and (M)ADT nearreal time and delayed-time products. CLS-DOS-NT-06-034, Issue 3.2, Collecte Localisation Satellites (CLS), p 58

Danabasoglu G et al (2014) North Atlantic simulations in coordinated ocean-ice reference experiments phase II (CORE-II). Part I: mean state. Ocean Model 73:76-107. https://doi.org/10.1016/j.ocemo d.2013.10.005

Fukamachi Y, Simuzu D, Ohshima KI, Eicken H, Mahoney AR, Iwamoto K, Moriya E, Nihashi S (2017) Sea-ice thickness in the coastal northeastern Chukchi Sea from moored ice-profiling sonar. J Glaciol 63:888-898. https://doi.org/10.1017/jog.2017.56

Giles KA, Laxon SW, Ridout AL, Wingham DJ, Bacon S (2012) Western Arctic Ocean freshwater storage increased by wind-driven spin-up of the Beaufort Gyre. Nat Geosci 5:194. https://doi. org/10.1038/ngeo1379

Good SA, Martin MJ, Rayner NA (2013) EN4: quality controlled ocean temperature and salinity profiles and monthly objective analyses with uncertainty estimates. J Geophys Res 118:67046716. https://doi.org/10.1002/2013jc009067

Haas C (2010) Dynamics versus thermodynamics: the sea ice thickness distribution. In: Thomas DN, Dieckmann GS (eds) Sea ice, 2nd edn. Wiley-Blackwell, Hoboken, pp 113-152

Hamilton D (1994) GTSPP builds an ocean temperature-salinity database. Earth Syst Monit 4:4-5

Hibler WD III (1979) A dynamic thermodynamic sea ice model. J Phys Oceanogr 9:815-846. https://doi.org/10.1175/15200485(1979)009\%3c0815:adtsim\%3e2.0.co;2

Hibler WD III, Walsh JE (1982) On modeling seasonal and interannual fluctuations of Arctic sea ice. J Phys Oceanogr 12:1514-1523

Holland MM, Bitz CM, Eby M, Weaver AJ (2001) The role of ice-ocean interactions in the variability of the North Atlantic thermohaline circulation. J Climate 14:656-675. https://doi. org/10.1175/1520-0442(2001)014\%3c0656:troioi\%3e2.0.co;2

Hunke EC, Dukowicz JK (1997) An elastic-viscous-plastic model for sea ice dynamics. J Phys Oceanogr 94:1849-1867

Hunke EC, Lipscomb WH (2006) CICE: the Los Alamos Sea Ice Model Documentation and Software User's Manual. LA-CC-9816, Los Alamos National Laboratory, p 59

Hunke EC, Lipscomb WH (2010) CICE: the Los Alamos Sea Ice Model Documentation and Software User's Manual Version 4.1. LA-CC-06-012, Los Alamos National Laboratory, p 76

Ikeda M, Shinkai H, Watanabe T (2004) Parametrization of thin ice in a coupled ice-ocean model: application to the seasonal ice cover in the Sea of Okhotsk. Atmos Ocean 42:1-12. https://doi. org/10.3137/ao.420101

Ito M, Ohshima KI, Fukamachi Y, Simizu D, Iwamoto K, Matsumura Y, Mahoney AR, Eicken H (2015) Observations of supercooled water and frazil ice formation in an Arctic coastal polynya from moorings and satellite imagery. Ann Glaciol 56:307-314. https:// doi.org/10.3189/2015aog69a839

Iwamoto K, Ohshima KI, Tamura T, Nihashi S (2013) Estimation of thin ice thickness from AMSR-E data in the Chukchi Sea. Int J Remote Sens 34:468-489. https://doi.org/10.1080/01431 161.2012.712229

Iwamoto K, Ohshima KI, Tamura T (2014) Improved mapping of sea ice production in the Arctic Ocean using AMSR-E thin ice thickness algorithm. J Geophys Res 119:3574-3594. https://doi. org/10.1002/2013jc009749

Kaleschke L et al (2016) SMOS sea ice product: operational application and validation in the Barents Sea marginal ice zone. Remote Sens Environ 180:264-273. https://doi.org/10.1016/j.rse.2016.03.009

Kobayashi S, Ota Y, Harada Y, Ebita A, Moriya M, Onoda H, Onogi K, Kamahori H, Kobayashi C, Endo H, Miyaoka K, Takahashi
K (2015) The JRA-55 Reanalysis: general specifications and basic characteristics. J Meteorol Soc Japan 93:5-48. https://doi. org/10.2151/jmsj.2015-001

Komuro Y (2014) The impact of surface mixing on the Arctic river water distribution and stratification in a global ice-ocean model. $\mathrm{J}$ Climate 27:4359-4370. https://doi.org/10.1175/jcli-d-13-00090.1

Kosugi N, Sasano D, Ishii M, Nishino S, Uchida H, Yoshikawa-Inoue $\mathrm{H}$ (2017) Low $\mathrm{pCO}_{2}$ under sea-ice melt in the Canada Basin of the western Arctic Ocean. Biogeosciences 14:5727-5739. https ://doi.org/10.5194/bg-14-5727-2017

Kurihara Y, Sakurai T, Kuragano T (2006) Global daily sea surface temperature analysis using data from satellite microwave radiometer, satellite infrared radiometer and in situ observations. Weather Bull 73:1-18 (in Japanese)

Kwok R, Cunningham GF (2008) ICESat over Arctic sea ice: estimation of snow depth and ice thickness. J Geophys Res 113:C08010. https://doi.org/10.1029/2008jc004753

Large WG, Yeager SG (2004) Diurnal to decadal global forcing for ocean and sea-ice models: the data sets and flux climatologies. NCAR Tech Note 460, CGD Division of the National Center for Atmospheric Research, Boulder

Large WG, Yeager SG (2009) The global climatology of an interannually varying air sea flux data set. Climate Dyn 33:341-364. https ://doi.org/10.1007/s00382-008-0441-3

Laxon S, Giles KA, Ridout AL, Wingham DJ, Willatt R, Cullen R, Kwok R, Schweiger A, Zhang J, Haas C, Hendricks S, Krishfield R, Kurtz N, Farrell S, Davidson M (2013) CryoSat-2 estimates of Arctic sea ice thickness and volume. Geophys Res Lett 40:1-6. https://doi.org/10.1002/grl.50193

Lindsay RW, Zhang J (2006) Assimilation of ice concentration in an ice-ocean model. J Atmos Ocean Technol 23:742-749. https:// doi.org/10.1175/jtech1871.1

Lipscomb WH (2001) Remapping the thickness distribution in sea ice models. J Geophys Res 106:13989-14000

Makynen M, Simila M (2019) Thin Ice detection in the Barents and Kara seas using AMSR2 radiometer data. IEEE Trans Geosci Remote Sens 53:1-20. https://doi.org/10.1109/tgrs.2019.2913283

Martin S, Drucker R, Yamashita K (1998) The production of ice and dense shelf water in the Okhotsk Sea polynyas. J Geophys Res 103:27771-27782. https://doi.org/10.1029/98jc02242

Martin S, Drucker R, Kwok R, Holt B (2004) Estimation of the thin ice thickness and heat flux for the Chukchi Sea Alaskan coast polynya from Special Sensor Microwave/Imager data, 1990-2001. J Geophys Res 109:C10012. https://doi.org/10.1029/2004jc002428

Maslanik JA, Fowler C, Stroeve J, Drobot S, Zwally J, Yi D, Emery W (2007) A younger, thinner Arctic ice cover: increased potential for rapid, extensive sea-ice loss. Geophys Res Lett 34:L24501. https ://doi.org/10.1029/2007g1032043

Matsumura Y, Hasumi H (2008) Brine-driven eddies under sea ice leads and their impact on the Arctic Ocean mixed layer. J Phys Oceanogr 38:146-163. https://doi.org/10.1175/2007jpo3620.1

Matsumura Y, Ohshima KI (2015) Lagrangian modelling of frazil ice in the ocean. Ann Glaciol 56:373-382. https://doi.org/10.3189/2015a og69a657

Mauritzen C, Rudels B, Toole J (2013) The arctic and subarctic oceans/ seas. In: Griffies S, Church G (eds) Ocean circulation and climate, 2nd edn. Academic Press, London, pp 443-464

McPhee M (2008) Air-ice-ocean interaction: turbulent ocean boundary layer exchange processes. Springer, New York

Meier WN, Maslanik JA, Fowler CW (2000) Error analysis and assimilation of remotely sensed ice motion within an Arctic sea ice model. J Geophys Res 105:3339-3356. https://doi. org/10.1029/1999jc 900268

Mellor GL, Kantha L (1989) An ice-ocean coupled model. J Geophys Res 94:10937-10954. https://doi.org/10.1029/JC094iC08p10937 
Murray RJ (1996) Explicit generation of orthogonal grids for ocean models. J Comput Phys 126:287-302

Nakata K, Ohshima KI, Nihashi S (2018) Estimation of thin-ice thickness and discrimination of ice type from AMSR-E passive microwave data. IEEE Trans Geosci Remote Sens 99:1-14. https://doi. org/10.1109/tgrs.2018.2853590

Naoki K, Ukita J, Nishio F, Nakayama M, Comiso JC, Gasiewski A (2008) Thin sea ice thickness as inferred from passive microwave and in situ observations. J Geophys Res 113:C02S16. https://doi. org/10.1029/2007jc004270

NASA Aquarius Project (2017) Aquarius Official Release Level 3 Rain-flagged Sea Surface Salinity Standard Mapped Image Daily Data V5.0. PO.DAAC CA USA. https://doi.org/10.5067/aqr50 -3y1ce. Accessed 26 June 2018

Nguyen AT, Menemenlis D, Kwok R (2009) Improved modeling of the Arctic halocline with a subgrid-scale brine rejection parameterization. J Geophys Res 114:C11014. https://doi.org/10.1029/2008j c005121

Nihashi S, Ohshima KI, Tamura T, Fukamachi Y, Saitoh S-I (2009) Thickness and production of sea ice in the Okhotsk Sea coastal polynyas from AMSR-E. J Geophys Res 114:C10025. https://doi. org/10.1029/2008jc005222

Nishino S, Itoh M, Williams WJ, Semiletov I (2013) Shoaling of the nutricline with an increase in near-freezing temperature water in the Makarov Basin. J Geophys Res Oceans 118:635-649. https:// doi.org/10.1029/2012jc008234

Ohshima KI, Nihashi S, Iwamoto K (2016) Global view of sea-ice production in polynyas and its linkage to dense/bottom water formation. Geosci Lett 3:13. https://doi.org/10.1186/s40562-016-0045-4

Proshutinsky A, Aksenov Y, Kinney JC, Gerdes R, Golubeva E, Holland D, Holloway G, Jahn A, Johnson M, Popova EE, Steele M, Watanabe E (2011) Recent advances in Arctic ocean studies employing models from the Arctic Ocean Model Intercomparison Project. Oceanography 24:102-113. https://doi.org/10.5670/oceanog.2011.61

Rabenstein L, Hendricks S, Martin T, Pfaffhuber A, Haas C (2010) Thickness and surface-properties of different sea-ice regimes within the Arctic Trans Polar Drift: data from summers 2001, 2004 and 2007. J Geophys Res 115:C12059. https://doi. org/10.1002/2009jc005846

Rousset C, Vancoppenolle M, Madec G, Fichefet T, Flavoni S, Barthélemy A, Benshila R, Chanut J, Levy C, Masson S, Vivier F (2015) The Louvain-La-Neuve sea ice model LIM3.6: global and regional capabilities. Geosci Model Dev 8:2991-3005. https://doi. org/10.5194/gmd-8-2991-2015

Schmidtko S, Johnson GC, Lyman M (2013) MIMOC: a global monthly isopycnal upper-ocean climatology with mixed layers. J Geophys Res 118:1658-1672. https://doi.org/10.1002/jgrc.20122

Serreze MC, Stroeve J, Barrett AP, Boisvert LN (2016) Summer atmospheric circulation anomalies over the Arctic Ocean and their influences on September sea ice extent: a cautionary tale. J Geophys Res Atmos 121:11463-11485. https://doi.org/10.1002/2016jd025161

Shimada K, Carmack EC, Hatakeyama K, Takizawa T (2001) Varieties of shallow temperature maximum waters in the Western Canadian Basin of the Arctic Ocean. Geophys Res Lett 28:3441-3444. https ://doi.org/10.1029/2001g1013168

Smolarkiewicz PK (1984) A fully multidimensional positive definite advection transport algorism with small implicit diffusion. J Comput Phys 54:325-362

Steele M, Zhang J, Rothrock D, Stern H (1997) The force balance of sea ice in a numerical model of the Arctic Ocean. J Geophys Res 102:21061-21079. https://doi.org/10.1029/97jc01454

Stringer WJ, Groves JE (1991) Location and areal extent of polynyas in the Bering and Chukchi Seas. Arctic 44:164-171

Tamura T, Ohshima KI (2011) Mapping of sea ice production in the Arctic coastal polynyas. J Geophys Res 116:C07030. https://doi. org/10.1029/2010jc006586
Tamura T, Ohshima KI, Markus T, Cavalieri DJ, Nihashi S, Hirasawa $\mathrm{N}$ (2007) Estimation of thin ice thickness and detection of fast ice from SSM/I data in the Antarctic Ocean. J Atomos Ocean Technol 24:1757-1772. https://doi.org/10.1175/jtech2113.1

Tomczak M, Godfrey JS (1994) Regional oceanography: an introduction. Pergamon, Oxford

Toyoda T, Fujii Y, Kuragano T, Matthews JP, Abe H, Ebuchi N, Usui N, Ogawa K, Kamachi M (2015) Improvements to a global ocean data assimilation system through the incorporation of Aquarius surface salinity data. QJR Meteorol Soc 141:2750-2759. https:// doi.org/10.1002/qj.2561

Toyoda T, Fujii Y, Yasuda T, Usui N, Ogawa K, Kuragano T, Tsujino H, Kamachi M (2016) Data assimilation of sea ice concentration into a global ocean-sea ice model with corrections for atmospheric forcing and ocean temperature fields. J Oceanogr 72:235262. https://doi.org/10.1007/s10872-015-0326-0

Toyoda T, Fujii Y, Kuragano T, Kamachi M, Ishikawa Y, Masuda S, Sato K, Awaji T, Hernandez F, Ferry N, Guinehut S, Martin MJ, Andrew Peterson K, Good SA, Valdivieso M, Haines K, Storto A, Masina S, Khl A, Zuo H, Balmaseda M, Yin Y, Shi L, Alves O, Smith G, Chang Y-S, Vernieres G, Wang X, Forget G, Patrick Heimbach O, Wang IF, Lee T (2017) Intercomparison and validation of the mixed layer depth fields of global ocean syntheses. Climate Dyn 49:753-773. https://doi.org/10.1007/s0038 2-015-2637-7

Tsujino H, Nakano H, Sakamoto K, Urakawa LS, Hirabara M, Ishizaki $\mathrm{H}$, Yamanaka G (2017) Reference manual for the Meteorological Research Institute Community Ocean Model (MRI.COM) version 4. Tech Rep 80, Meteorological Research Institute, p 284. https:// doi.org/10.11483/mritechrepo.80

Tsujino H, Urakawa LS, Nakano H, Small RJ, Kim WM, Yeager SG, Danabasoglu G, Suzuki T, Bamber JL, Bentsen M, Boning CW, Bozec A, Chassignet EP, Curchitser E, Dias FB, Durack PJ, Griffies SM, Harada Y, Ilicak M, Josey SA, Kobayashi C, Kobayashi S, Komuro Y, Large WG, Le Sommer J, Marsland SJ, Masina S, Scheinert M, Tomita H, Valdivieso M, Yamazaki D (2018) JRA-55 based surface dataset for driving ocean-sea-ice models (JRA55-do). Ocean Model 130:79-139. https://doi.org/10.1016/j. ocemod.2018.07.002

Uotila P, Goosse H, Haines K, Chevallier M, Barthelemy A, Bricaud C, Carton J, Fuckar N, Garric G, Iovino D, Kauker F, Korhonen M, Lien VS, Marnela M, Massonnet F, Mignac D, Peterson KA, Sadikni R, Shi L, Tietsche S, Toyoda T, Xie J, Zhang Z (2019) An assessment of ten ocean reanalyses in the polar regions. Climate Dyn 52:1613-1650. https://doi.org/10.1007/s00382-018-4242-z

Urakawa LS, Tsujino H, Nakano H, Sakamoto K, Yamanaka G (2017) Global ocean model development for CMIP6 in Meteorological Research Institute and its performance in reproducing ocean general circulation. In: JpGU-AGU Joint Meeting 2017, Makuhari, Japan. Jpn Geophys Union, AOS19-03. https://confit.atlas.jp/ guide/event/jpguagu2017/subject/AOS19-03/tables

Yamamoto-Kawai M, McLaughlin FA, Carmack EC, Nishino S, Shimada K, Kurita N (2009) Surface freshening of the Canada Basin, 2003-2007: river runoff versus sea ice meltwater. J Geophys Res 114:C00A05. https://doi.org/10.1029/2008jc005000

Yi D, Zwally HJ (2009) Arctic sea ice freeboard and thickness, version 1. National Snow and Ice Data Center. https://doi.org/10.5067/ sxjvj3a2xizt

Publisher's Note Springer Nature remains neutral with regard to jurisdictional claims in published maps and institutional affiliations. 